\title{
Teaching Law And Educating Lawyers: Closing The Gap Through Multidisciplinary Experiential Learning
}

\section{Alan M. Lerner ${ }^{\dagger}$ and Erin Talati}

\section{Summary}

Interdisciplinary legal education found its roots nearly a century ago, but recently there has been a renewed trend both in the literature and in practice to increase interdisciplinary opportunities in clinical and scholarly activities. In the classroom, proponents have argued that interdisciplinary education is essential to understanding the cultural and social contexts in which legal conflicts arise. Additionally, scholars praise the interdisciplinary model - in both teaching and practice - for its tendency to generate a higher level of thinking from those considering problems from diverse viewpoints. The use of interdisciplinary models also promotes mutual respect between professionals from different disciplines, a working knowledge of the domain of another discipline, enhanced communication through learning both the mechanisms and vocabulary of other professions, and increased understanding another discipline's "rules, beliefs, and ethical principles." Finally, creating an interdisciplinary framework can enhance the efficacy of the lawyer's problem solving efforts through providing a means by which goals, strategies, and unique insights of different "helping professions" can be united in pursuit of a common purpose.

The value that interdisciplinary approaches offer is often sharply countered by the challenges it creates. The most common challenges are those created by perceived or actual role boundaries within individual professions and the process of professional socialization that occurs during traditional legal training. Although this first criticism is challenging, it is not impossible to overcome. The second barrier to productive interdisciplinary work is also mutable, and reversing a socialization process that disfavors interdisciplinary experiences should therefore be a primary focus of legal educators. This paper proposes that

$\dagger$ Practice Professor of Law, University of Pennsylvania Law School

+ MD/JD, University of Pennsylvania, 2007
We are deeply indebted to our colleagues Dr. Cindy Christian, and Diane Smith-Hoban, MSW, whose vision, energy, creativity and courage were essential to the creation and growth of the collaboration that is the Interdisciplinary Child Advocacy Clinic. 
interdisciplinary advocacy for children involved in the child welfare system provides an intense experiential learning process, which engages students in a mutually dependent relationship with students from other disciplines and promotes long-term appreciation and facility for interdisciplinary work. It describes this experience in the context of one such clinic, providing a model for the development of future interdisciplinary endeavors.

\section{INTRODUCTION}

When I enrolled in the child advocacy clinic, I knew that it would present a wholly different experience than the ones to which I had become accustomed. Although I have been acutely and vocally aware of some of the constraints of the law school curriculum, the one thing you can say of introductory law school courses is that they are emotionally safe. As far as I am aware, no one has experienced any emotional damage from reading the Erie decision in a basic civil procedure course. Of course, that may be due to the simple fact that no one has ever experienced any emotion at all during that kind of experience. ${ }^{1}$

Traditionally, legal educators - almost exclusively professors trained in law - have focused their students' learning on the theory and doctrine of "the law," the structure of the legal system and its institutions, and the profession's analytical and problem solving processes. In law and most other schools for professional training, professional education also means focusing, with laser-like singularity of purpose, on the students' cognitive powers to the exclusion of their values and emotional systems. That focus, intended to teach law students "to think like lawyers," has produced, we believe, a narrowing of the students' vision about themselves as professionals. ${ }^{2}$ Lawyers learn that they work in legal environments with other lawyers, judges, or related legal actors, analyzing legal problems using legal materials and legal analysis, and that, at least by implication, with the exception of occasional reference to "expert witnesses" there is little need or space to collaborate with persons trained in other disciplines, let alone non-professionals.

We agree that being a lawyer requires those analytical skills. However, being a lawyer, as opposed to a scholar-teacher of law, means providing services to individual and institutional clients, often in extremely trying, high stakes circumstances in which other disciplines may be of critical importance to achieving the client's goals. Being a lawyer means facing ethical choices daily. And when collaborating with professionals from other disciplines, looming ethical issues may require harmonizing conflicting ethical mandates. Furthermore, being a lawyer means participating in a self-regulating profession that possesses a virtual monopoly on the critical positions in the formal legal system that administers justice for the entirety of society, and has special training, and therefore special position and power in the legislative and executive branches of the government at all levels.

In such circumstances, collaboration is essential if lawyers are to advance their clients' best interests, fulfill the promise of their profession, and assure that the machinery of government in general, and of justice in

1 Clinical Law Student (2003) (journal entry, on file with author). The interdisciplinary clinic discussed in this paper uses journaling as an educational tool to reflect on the implications of students' daily experiences, and as a means for clinic students to process much of the intense emotion that results from their casework. Throughout this paper, a number of student journal entries, with the author's identification removed, will be featured. For further discussion of journaling see infra Part II.B.4.b (discussing journaling as a tool for managing reactions to work).

2 WILLIAM M. SULLIVAN ET AL., EDUCATING LAWYERS: PREPARATION FOR THE PROFESSION OF LAW (Jossey-Bass 2007) [hereinafter Carnegie Report]. 
particular, functions in a legally and morally appropriate manner. ${ }^{3}$ Yet, as a consequence of the narrowness of their training lawyers may not even realize the breadth and variety of their roles, the importance of other disciplines in carrying them out, or their own limitations as lawyers in fulfilling them.

This paper will argue that effective education of lawyers must, and can, prepare them to collaborate with other professionals in both fully understanding, and achieving their clients' goals, and in fulfilling the lawyers' roles as members of the legal profession and participants in the democratic system of governance. Part I of the discussion examines the principles underlying traditional legal education and provides a basis for encouraging change. Part II discusses generally the history of collaboration within the legal profession, and specifically a collaboration within the Interdisciplinary Child Advocacy Clinic at the University of Pennsylvania Law School. Part III considers potential barriers to collaborative work but concludes that planning and commitment can overcome these obstacles and permit the benefits of interdisciplinary collaboration to be recognized.

\section{TRADITIONAL LEGAL EDUCATION}

\section{A. A Bit of History}

The study of law is ancient, and it is fair to assume that as long as there has been legal discourse, there have been scholars and teachers of the law. Since at least the time of the Enlightenment, the great universities throughout the world have been developing similar models of pedagogy for teaching post-secondary students: lectures, seminars, and tutorials taught by established scholars in the particular discipline. But advanced education was. until modern times, the exclusive province of those who were wealthy, powerful, or committed to organized religions.

Despite the long history of the study of law, lawyers as we know them today - advocates for clients, available to a broad swath of the citizenry regardless of class - are a relatively recent phenomenon. The education of lawyers in a university setting is even more recent. Although Sir William Blackstone began delivering his lectures on English law in the mid 18th century, the primary training model for British lawyers from the middle ages through the mid 20th century has been apprenticeship, centered in Inns of Court. 4 Similarly, although the United States Constitution is the product of the work of, among others, famous lawyers including Thomas Jefferson, John Adams, and James Monroe, none of the founding fathers, and none of the country's first generations of lawyers - including Jefferson, John Adams, John Quincy Adams, Andrew Hamilton, Patrick Henry, James Monroe, John Marshall and even Joseph Storey and Abraham Lincoln for

3 Legal academic literature contains a rich history of thoughtful analysis and recommendations to make the education of lawyers better suited to the needs of lawyers, the profession, and the clients they serve. See, e.g., Jerome Frank, Why Not a Clinical Lawyer-School?, 81 U. PA. L. REV. AND LAW REGISTER 907 (1933); Anthony G. Amsterdam, Clinical Legal Education - A 21st Century Perspective, 34 J. LEGAL EDUC. 612 (1984); Report of the Task Force on Law Schools and the Profession: Legal Education and Profession Development - An Educational Continuum, 1992 A.B.A. SEC. OF LEGAL EDUC. AND ADMISSIONS TO THE BAR; Phillip Areeda, Always a Borrower: Law and Other Disciplines, 1988
DUKE L.J. 1029 (1988); Carnegie Report, supra note 2, at 45. ("The Challenge is to align the practices of teaching and learning within the professional school so that they introduce students to the full range of the domain of professional practice while forming habits of mind and character that support the students' lifelong growth into mature knowledge and skill.").

4 See RAYMOND COCKS, FOUNDATIONS OF THE MODERN BAR (Sweet $\mathcal{G}$ Maxwell 1983) [hereinafter Cocks, FOUNDATIONS]; RAYMOND COCKS, SIR HENRY MAINE: A STUDY IN VICTORIAN JURISPRUDENCE (Cambridge Univ. Press 1988) [hereinafter Cocks, VICTORIAN JURISPRUDENCE]. 
that matter - earned university degrees in law. 5 They and their contemporaries learned their profession as apprentices. 6

Although there have long been appointed lecturers in law at a number of colleges and universities, the modern American law school can be traced to the efforts of Joseph Storey at Harvard in the early 19th century, as well as those of Harvard President Charles Eliot and his selection as the dean of the law school, Christopher Columbus Langdell, after the Civil War.7 From that point on the post-baccalaureate professional school model steadily squeezed out the apprenticeship model of legal education in the United States until, by the late 20th century, apprenticeship as a means of becoming a lawyer had all but disappeared. Langdell's theory and methodology reflected that used to teach post-secondary school philosophy, history, mathematics, biology, etc. It assumed that law is a science and should be taught from original documents - statutes, and, given the fact that ours was a common law jurisdiction, the decisions of appellate courts. In this model, individuals steeped in the knowledge base, structures, procedures, and values of the particular discipline lecture to students or guide them using reading and writing assignments, Socratic dialogue, large classes, smaller seminars, and individual tutorials, towards the goal of the students learning the theory, principles, and doctrine comprising the body of knowledge of the discipline. In law, that body consists of legal rules organized into a variety of legal "cubbyholes," e.g., contacts, torts, criminal law, civil procedure, etc., the structure of the legal systems in which they operate, and a system of critical analysis used by legal academics, lawyers and judges (i.e., "thinking like a lawyer"), taught through the "Socratic Dialogue". 8

In the prevailing systems throughout the world, the basic model for teaching law is housed in universities alongside departments devoted to teaching other disciplines in similar pedagogic models, and law graduates receive the same undergraduate degrees (e.g., B.A. or B.S.) with their major field of study being "Law." In the United States, and a few other jurisdictions, the teaching of law is housed in post-university level colleges of law which offer the degree of Juris Doctor (J.D.). In all of these systems, however, law students study law with other law students under the tutelage of law-trained professors using the same basic teaching methods and materials as the professors used when they studied law. 10 While the theory and pedagogy begat through the lineage of Storey and Langdell and the post-middle ages European universities does an excellent job of teaching the theory and doctrine of "the law" and formal legal analysis, it has not succeeded in teaching the craft of "lawyering," nor the roles of advocate and counselor for clients, member of the

5 Daniel R. Coquillette, The Legal Education of a Patriot: Josiah Quincy Jr.'s LAW COMMONPLACE (1763), ARIZ. ST. L.J. (forthcoming summer 2007), available at http://ssrn.com/abstract $=949331$ (manuscript at 4) (discussing the rigor of much of the legal apprenticeship training in the United States in the 18th and 19th centuries).

$6 \mathrm{Id}$.

7 Id., see also Carnegie Report, supra note 2, at 4-6 (discussing the evolution of the modern model of legal education in the United States from the divergent paths of European universities and British apprenticeships).

8 See Coquillette, supra note 5, at 7-9 (describing Eliot and Langdell's distillation of law into science at Harvard Law and the profound change it wrought in popular conceptions of the law); Carnegie Report supra note 2, at 4-6 (discussing the theory of legal education espoused by Joseph Storey and Christopher Columbus Langdell ).
9 The J Doctor degree is actually a recent creation. Around 1970, American law schools began to replace the Bachelor of Laws degree, the L.L.B., with the Juris Doctor degree. See, e.g. J.D.s Now Available for Alumni, N.C. L. Rec. 1, 5 (UNC Law School Student Bar Association, Chapel Hill, N.C.) (Jan 1970).

10 Up until the late 19th century, most legal education in the United States was in the form of apprenticeship with licensed practitioners. Following on the teachings of Harvard professor Christopher Columbus Langdell, who taught that law is a science and that its study should parallel that of other arts and sciences, legal education in the United States moved from apprenticeship to its present form in law departments and schools either free-standing or as part of a college or university. Jack M. Balkin and Sanford Levinson, Law and the Humanities: An Uneasy Relationship, 18 YALE J.L. Eु HUMAN. 155, 159 (2006) ("Langdell's avowed mission was to transform American legal education into 'scientific analysis' ....."). 
profession, or public citizen. ${ }^{11}$ At least in part this can be traced to the fact that law teachers are, for the very most part, professors with little or no experience practicing law, and their experience and interest is in legal theory and doctrine, not in the roles and work of the practicing lawyer. ${ }^{12}$

Over the centuries, this system has produced many brilliant scholars of the law. Continued progress, however, may require change. ${ }^{13}$

\section{B. Preliminary Assumptions: The Legal Academy's "Articles of faith"}

For many years, law schools around the world - both undergraduate and graduate - have shared several of what might be called "articles of faith" about legal education:

1. In law school we teach students to think like lawyers.

2. The cornerstone of thinking like a lawyer is abstract critical analysis, or critical thinking.

3. The process that we call critical analysis or critical thinking is the same in all contexts.

4. Lawyers work in legal environments with other lawyers, judges, or related legal actors.

5. With the exception of "expert witnesses" there is little need or space to collaborate with persons trained in other disciplines, let alone with non-professionals.

6. Lawyers, as representatives of their clients, are bound by a "role morality" such that their individual values are either irrelevant, or at most subservient to the goals of the client, and the standards of professional responsibility imposed by local laws and practice.

7. The emotions of the lawyer are irrelevant except insofar as they might get in the way of critical legal thinking, and thus should be actively repressed.

8. Justice is a "legal" concept, defined, structured and achieved by lawyers for their clients, and relates, essentially, to achieving for one's client whatever the law provides for her in a given situation.

If these shared articles of faith were true, it would not be a great challenge to train lawyers to do estimable work for their clients, the profession and the community. Students could be taught the relevant theoretical and doctrinal principles, applicable legal systems, procedures, and sources of law, and to apply their classical critical legal analysis to whatever legal problem came their way. And, Voila! Lawyers!

11 Carnegie Report, supra note 2, at 4-6, 19, 26-30 (indicating that the effective practice of law is actually three different, though related and integrated, activities including analysis of legal and related materials, being an advocate and counselor for clients, and participation in the profession as a member and as a public citizen, and arguing that reducing law to science permits the effective teaching of theory, doctrine and analysis but fails to teach how to understand and execute the other two roles of the professional.); Alan M. Lerner, Using Our Brains: What Cognitive Science and Social Psychology Teach Us about Teaching Law Students to Make Ethical, Professionally Responsible Choices, 23 QUINNIPIAC L. REV. 643 (2004) [Hereinafter Lerner, Using Our Brains] (arguing that developing the critical elements of "role" and lawyering skills essential to the effective practice of law requires experiential teaching and learning); Paul Brest, The Responsibility of Law Schools: Educating Lawyers as Counselors and Problem Solvers, 58 LAW $\mathcal{G}$ CONTEMP. PROBS. 5, 6 (1995) (criticizing law schools' failure to adequately to prepare students in skills beyond doctrine and legal analysis).

12 Carnegie Report, supra note 2, at 4-6 (arguing that the triumph of the Storey/Langdell approach to legal education necessarily replaced apprentice masters, who had been drawn from the ranks of experienced practitioners, with "scholar-teachers").

13 See Carnegie Report, supra note 2, at 12 ("[Law schools face an] increasingly urgent need to bridge the gap between analytical and practical knowledge.") 


\section{Teaching Law versus Educating Lawyers - The Three-Pillared Apprenticeship}

Modern legal education is, however, or should be, different from the education appropriate in the arts and sciences for at least two reasons. First, the subject matter - law - differs in at least one critical facet from the "sciences": law reflects human choices to govern our behavior based upon our values, and thus can validly differ significantly from jurisdiction to jurisdiction in ways not applicable to the sciences. ${ }^{14}$ Additionally, legal education differs critically in its role in society from education in other of the arts and sciences taught at the post-secondary school level. In every discipline from African History through Zoology, graduates who remain in the discipline generally pursue careers based upon their studies in that discipline by further research and scholarship limited to that discipline. Their hard work and creativity expand the knowledge base in that discipline, which they, in turn, teach to each new crop of students. Not so in law. True, some law graduates pursue careers in the legal academy using essentially the same analytical and research tools they learned in law school. Yet the vast majority leave the academy to become practicing lawyers responsible not to advance the knowledge base of the law and teach it to others, but rather to serve the expressed goals and needs of their clients, and to contribute to the development of the legal rules and systems which govern our society. 15

Clients, as any practicing lawyer knows, are complex creatures, constrained by the contexts of their lives and communities, with a plethora of goals, concerns, needs, and desires, and are frequently faced with other persons or entities seeking contrary or inconsistent goals. The legal problems that most clients present to their lawyers represent only a small piece of their lives, inextricably intertwined with other important issues they face. Knowing the law and being able to analyze legal theory and doctrine are necessary to assist clients to solve their problems - whether those problems arise under the rubric of litigation, transactions or personal planning - but they are not sufficient. The skills and craft of the professional must be brought to bear as well. ${ }^{16}$ At the same time, the fundamental and pervasive role that law, and thus lawyers and the legal profession, plays in the maintenance of a free society suggests that attempting to abstract legal analysis from values may be at the least undesirable, and perhaps impossible. Those considerations should move us to re-examine the "articles of faith". ${ }^{17}$ Doing so, we submit, should lead the legal academy to significantly change how it prepares law students to be effective, responsible lawyers for their clients, and important contributors to the system of law that governs our lives. How to do that?

14 Consider merely the significant structural and procedural differences between systems based upon the common law (i.e., the Anglo-American model) and those based upon a code (i.e., the Continental model); or between an inquisitorial and adversarial model of the law's response to crime.

15 Thus, while lawyers' activities do contribute to the development of the law, particularly in common law jurisdictions, that development is driven not so much by their personal values, but rather by the goals and values of their clients, which may be quite different. See MODEL RULES OF PROFL CONDUCT R. 1.2(b) ("A lawyer's representation of a client ... does not constitute an endorsement of the client's political, economic, social, or moral views or activities.").

16 Some in the legal academy suggest that teaching the roles and craft of the lawyer beyond teaching students "to think like lawyers" is properly left to the profession after the students graduate from law school. We would respectfully disagree for two reasons. First, although some law graduates secure employment in institutions (e.g., law firms, large corporate or governmental law departments), many go directly from law school to the bar examination to practicing law as sole practitioners, or in settings not equipped to provide that post-law school "apprenticeship," and the profession has no mechanisms for providing it. Second, if all that law school is about is the teaching of legal analysis, legal theory and doctrine, perhaps it should be located in the undergraduate university, as it is in most of the world, leaving for the post-graduate teaching the other roles and skills of the modern lawyer.

17 See Carnegie Report, supra note 2, at 26-28 (learning through apprenticeship with experts teaches not only the subject matter, but also its application according to the norms of the profession); Lerner, Using Our Brains, supra note 11, at 661 (suggesting that if our goal is to prepare our students to become practicing lawyers in the highest sense of that term, our knowledge of cognitive development suggests a different kind of learning in law school); Howard Lesnick, Infinity in a Grain of Sand: The World of Law and Lawyering as Portrayed in the Clinical Teaching Implicit in the Law School, 37 UCLA L. REV. 1157, 1158 (1990) [Hereinafter Lesnick, Infinity in a Grain of Sand] (indicating a need for re-examination of our implicit teaching). 
It is now widely understood that the apprenticeship model is extraordinarily effective in teaching students the "how" and "why" of a discipline, and the role of the members of that discipline in a community of fellow practitioners, as well as their role in the larger community. ${ }^{18}$ The Carnegie Report took a close look at the teaching of law students "to think like lawyers," and concluded that this process is well taught in the current model, with experienced and knowledgeable practitioners of that process guiding them through their reading and understanding of legal theory and doctrine as they develop their analytical skills. However, those same professors do not seek to teach the other two apprenticeships: the craft of being a practicing lawyer for clients, and the role of a member of the self-regulating profession holding special responsibility for the law, legal system and administration of justice throughout society. This paper challenges the notion that law schools need only teach legal analysis from legal materials, arguing that to do so produces lawyers who are not adequately equipped to serve their clients' needs, even their identified "legal needs" or the needs of their profession or communities. While it makes reference to a variety of other disciplines with which collaboration is critical for lawyers, especially lawyers for the poor and disenfranchised, it focuses primarily on the work of lawyers for children and parents in so-called "child welfare" or "child protection" cases because for the past five years the first author has been teaching and supervising students in an Interdisciplinary Child Advocacy Clinic, and has come to experience, firsthand, the critical relationship between meeting the goals of our clients and collaboration between and among several disciplines. ${ }^{19}$ In that context it seeks to demonstrate how all three apprenticeship pillars can be combined effectively in a single, multi-disciplinary apprenticeship experience - and contribute to the effective education of lawyers.

\section{LAWYERING FOR REAL CLIENTS - COLLABORATION IN CHILD ADVOCACY}

Every year, between 3000 and 4000 new child dependency cases are filed in the Family Court Division of the Court of Common Pleas of Philadelphia County. 20 These cases involve children who, it is alleged, have been abandoned, abused or neglected, or are otherwise without proper parental care or supervision. ${ }^{21}$ Virtually all of these children come from the poorest of the poor families in our community. They and their families usually have multiple needs including those medical, psychological, educational and economic, and frequently are also dealing with issues of substance abuse. Too often, the various public and private providers of the services required to assure the safety and well being of these children are under-resourced and unable to coordinate their services in the particular manner that each child needs. Moreover, in many cases the

18 See Lerner, Using Our Brains, supra note 17 at 705 (arguing that pervading early law school courses with ethical examples is the best way to teach responsiveness to them); Carnegie Report, supra note 2, at 27-29 (incorporating apprenticeships into education allows students to synthesize what they have learned and use it professionally); Coquillette, supra note 5, at 6(explaining that "elite legal apprenticeship" was actually a highly organized procedure that produced very capable lawyers).

19 For a demonstration of the clinic's multidisciplinary approach to addressing client goals, see Appendix A (detailing a case study adapted from an actual case handled by the University of Pennsylvania Law School Interdisciplinary Child Advocacy Clinic).

20 Every state in the United States has statutes that purport to protect children from abuse and neglect and authorize the state to intervene, ultimately through the courts, to provide protective services. See generally Keeping Children and Families Safe Act of 2003, Pub. L. No. 108-36 (2003) (amending the Child Abuse Prevention and Treatment Act, which mandates a minimum federal definition of abuse and neglect and provides funding for state programs addressing child welfare). These services include, but are not limited to, services to the children and the family with which the child lives, removal from the home and placement in foster care, escalating in some cases to termination of parental rights and adoption. Each state has its own terminology for the proceedings, the state agency and the particular courts in which these proceedings originate. Throughout this article we will use the terms applicable in Pennsylvania, generally, and Philadelphia in particular, unless otherwise noted.

2142 Pa. C.S.A. $\$ 6302$ (providing a definition for a finding of dependency). 
role of advocate for children has become distinctly anti-parent, exacerbating rather than reducing the tension between parent and child - both of whom need assistance from the state.22 In creating an Interdisciplinary Child Advocacy Clinic, we strove to build a model that would demonstrate a route to overcoming this dysfunctional disorganization and conflict.

\section{A. Appreciating Multidisciplinary Collaboration}

We envisioned a clinical model that sought integration over fragmentation, and collaboration wherever appropriate rather than a purely adversarial stance - a model that enveloped the children and families the clinic serves in comprehensive services, which eventually would lead towards safe and timely reunification. Collaboration works. The concept of collaboration, now motivating building designers to rethink spatial design in workplaces, ${ }^{23}$ enjoys unique benefits in the legal profession. Yet, consistent with conventional models of legal thought and education, legal scholars traditionally do not collaborate, ${ }^{24}$ either with other lawyers or with individuals outside of the profession of law, despite the intrinsic scholarly, educational, and client-centered service benefits inherent to the practice of collaboration.

\section{From Intradisciplinary to Interdisciplinary Collaboration}

Compared to other academic disciplines, historically, the legal academy has not been considered the collaborative type. Looking at instances of co-authorship in law journals reveals a much lower rate of collaboration between lawyers than between professionals in the social sciences. For example, between 1970 and 1999 the rate of intradisciplinary collaboration between legal professionals was only fifteen percent. ${ }^{25}$ During that same period, collaboration among professionals in the social sciences reached sixty percent. ${ }^{26}$ Moreover, the influence of early legal collaborations on the development of legal thought seems small compared to the influence of non-collaborative works. ${ }^{27}$ Despite the discouraging trend with respect to collaboration in legal ventures, indicators suggest that productive collaboration is on the rise. ${ }^{28}$ Younger scholars participate in more collaborative ventures than their more senior colleagues, suggesting that, within the discipline of law and legal scholarship, there is an emerging readiness to recognize the value of collaboration. ${ }^{29}$ Similarly, scholars perceive recent collaborations to be more influential than earlier collaborations. 30

22 See, e.g., MARTIN GUGGENHEIM, WHAT'S WRONG WITH CHILDREN'S RIGHTS 213-306 (Harvard University Press 2005) [Hereinafter Guggenheim,Children's Rights]; Martin Guggenheim, How Children's Lawyers Serve State Interests, 6 NEV. L. J. 805 (2006) [Hereinafter Guggenheim, Children's Lawyers] (Guggenheim argues that under the Constitution, and historical and biological reality, parents have rights and children have needs. Giving children legally enforceable rights as opposed to the rights of their parents, he argues, serves other adults' interests, including those of the state actors wishing to interfere with the family in regulatory and punitive ways, but does not serve the needs of either the children or their families).

23 See Eils Lotozo, Tearing down the walls: Think outside the cubicle: Workplace redesigned with interaction in mind, THE PHILADELPHIA INQUIRER, Sept. 1, 2006 ("The new trend in workplace design... focuses on how people collaborate and get things done.").

24 See supra Part I.B. (outlining the conventional model as a set of legal "articles of faith").
25 See Tracey E. George $\mathcal{B}$ Chris Guthrie, Joining Forces: The Role of Collaboration in the Development of Legal Thought, 52 J. LEGAL EDUC. 559, 562 (2002) (investigating the role of collaboration in legal scholarship compared to other disciplines).

26 See id. at 568 ("During the last three decades of the twentieth century... . [s]ix out of every ten social science articles were the product of collaboration.").

27 See id. at 569 (measuring influence by the number of times an article has been cited).

28 See id. at 572-73 (describing factors creating an increase in collaborative endeavors and their influence).

29 See id. at 576 ("Collaboration is even more common among prominent younger scholars. ...").

30 See id. at 572 (commenting that the rate of citation for coauthored pieces is higher for more recent articles); see also Ian Ayres and Frederick E. Vars, Determinants of Citations to Articles in Elite Law Reviews, 29 J. LEGAL STUD. 427, 439 (2000) (finding that "[c]oauthored articles were cited more frequently than single-author pieces"). 
The increase in intradisciplinary collaboration offers the potential to recognize the important benefits of joint effort. Intradisciplinary collaboration adds critical skills and thought processes to legal education and promotes the early professional development of emerging legal thinkers. ${ }^{31}$ Collaboration can also present opportunities to reinforce faculty relationships with other legal faculty. ${ }^{32}$ Additionally, collaboration with practitioners provides an occasion to bridge theory and practice. 33 "Finally, legal scholarship is becoming increasingly interdisciplinary. . . Collaboration with academics from other disciplines brings nonlegal scholars' ideas and methodologies into legal scholarship, increases the likelihood that law faculty will produce empirical, interdisciplinary work, and improves the standing of legal academia in the broader academic community." 34 The increase in intradisciplinary collaboration indicates the beginning of a shift in the legal climate from the legal academic as sole actor to the legal academic as team player. This shift alone has produced benefits within the legal academy and the practice of law generally. Notwithstanding the benefits attributable to the movement towards intradisciplinary collaboration within the legal academy, lawyers and legal academics have much to gain from working with professionals outside of their discipline. Still, translating interdisciplinary scholarship into experiential interdisciplinary collaboration for law students has yet to take hold. ${ }^{35}$

\section{Interdisciplinary Collaboration}

Whatever the power - even the necessity - of the disciplines ... in the end, questions never stop at the boundaries of a discipline. Efforts to develop decisive and personal ideas of the true, the beautiful, and the good necessarily take us beyond specific disciplines and invite syntheses. 36

This reality and its realization form the essence of this discussion. For the lawyer, answering the question, remedying the problem, and finding the solution are the essential ends. But the most successful lawyers will reach beyond the legal question posed by the client to more fully understand the nature and context of the problem, because doing so is essential to finding the most effective means to achieve the client's goals. In so doing, the lawyer may have to consult and collaborate with clients and constituents, organizers and advocates, indeed, with anyone who can offer a unique and relevant perspective. Assessing the effectiveness of such interdisciplinary collaboration for law students can be approached using the same metrics applied to collaborative efforts between legal professionals, by examining the impact of the collaboration on four aspects of the legal profession: the practice of the profession, 37 enhancing professionalism and preparing future leaders, ${ }^{38}$ furthering legal scholarship, ${ }^{39}$ and educating future professionals. ${ }^{40}$ We submit that

31 See George and Guthrie, supra note 26, at 579 ("Collaboration with students provides uncommon pedagogical benefits and may spawn promising academic careers.").

32 See id. at 579 ("Collaboration with other law teachers strengthens relationships within and between law faculties.").

33 See id. at 579("Collaboration with judges, practicing lawyers, and other nonacademics produces scholarship that reflects both theoretical and real-world insights.").

34 Id. at 578-79.

35 There is an important distinction between interdisciplinary scholarship, cross-disciplinary course registration, and multidisciplinary collaboration. This distinction exists, in part, because most academic work in law and other disciplines in which law students take courses assesses students based upon performance on written examinations and/or research papers - activities in which experiential collaboration of the sort described here is generally prohibited.

36 HOWARD GARDNER, THE DISCIPLINED MIND: WHAT ALL STUDENTS SHOULD UNDERSTAND 147 (1999).

37 See infra Part II.A.2.a (considering interdisciplinary work as a vehicle to promote client goals).

38 See infra Part II.A.2.b (discussing interdisciplinary collaboration in the context of professional development).

39 See infra Part II.A.2.c (exploring the influence of interdisciplinary collaboration on legal scholarship).

40 See infra Part II.A.2.c (acknowledging the value of interdisciplinary work in legal education). 
examining these domains will demonstrate that while there are challenges to such engagements, ${ }^{41}$ the advantages attributable to interdisciplinary work support increasing the practice, particularly in the context of clinical legal education.

\section{a. Collaboration Facilitates "Whole Client"-Centered Service}

Reflecting on this semester's experience as a part of the Child Advocacy Clinic, there is one lesson I have learned that stands out in importance and meaningfulness. The role of the child advocacy team and each of its disciplines is to ensure that children in the child welfare system are not forgotten by society and the system itself. Advocating for their best interests in safety, academics, physical and mental health, and overall well-being is our mission, and as I have learned over and over, it is a critical one. ${ }^{42}$

Clients, as the recipients of services provided by professionals, are situated to most clearly reap the benefits of interdisciplinary collaboration. This discussion has already alluded to a number of client benefits, but their importance warrants explicit consideration. Collaboration first can enable a broader understanding of a client's problem by clarifying the social, economic, familial, and cultural frameworks in which legal conflicts arise. ${ }^{43}$ But collaboration helps throughout the entire process of representation. Despite a client's framing of her issue in legal terms when she brings it to her attorney, many client problems involve multiple dimensions. ${ }^{4}$ Collaboration provides all participants with a working knowledge of another discipline. It also sensitizes each to be alert for evidence that there are issues, or potential solutions, with respect to which another discipline might have valuable insights. This recognition of the role and potential contribution that other disciplines might make supports all members of a collaborative team to identify those aspects of a client's situation that benefit from the involvement of another professional. By understanding the various ways in which a client's problem may be framed through interaction with professionals who may encounter the problem in different contexts, the lawyer is better able to provide service to her client. Moreover, collaboration serves to enhance communication between professionals in various disciplines, facilitating the provision of services to the client. This communication is critical to effectively serving a client because no lawyer can learn all of the extra-disciplinary knowledge necessary to find the most appropriate outcome for her client. ${ }^{45}$ Learning how to communicate with the professionals who can help the client to obtain her goals, may additionally increase a client's satisfaction with the services she receives.

41 See infra Part III (addressing the challenges of multidisciplinary collaborative work).

42 Clinic Social Work Student (2006) (journal entry, on file with author)

43 See Anita Weinberg and Carol Harding, Interdisciplinary Teaching and Collaboration in Higher Education: A Concept Whose Time Has Come, 14 WASH. U. J.L. E⿱ POL'Y 15, 19 (2004) (explaining that this factor motivated early collaborations between philosophers, economists, and lawyers). See also, DAVID A. BINDER, PAUL BERGMAN, SUSAN C. PRICE AND PAUL $R$. TREMBLAY, LAWYERS AS COUNSELORS 2-13 (Thompson West, 2004) (advocating "client-centered" lawyering because the clients both "own" and thus live with their problems and attempted solutions, and also because clients know so much more about the larger context of their lives in which the particular problem has arisen).

44 See Janet Weinstein, Coming of Age: Recognizing the
Importance of Interdisciplinary Education in Law Practice, 74 WASH. L. REV. 319, 319 (1999) ("Courses in client counseling and mediation have long recognized that people are not one-dimensional and neither are their problems.").

45 Id. at 320 ("[Society] can expect lawyers to know how to work with people who together have the knowledge and skills required to assist a client in [a multi-dimensional] way."). Motivated by physicians who recognized that even the best medical science cannot alone provide healthy outcomes for patients, Boston Medical Center now employs lawyers as advocates for patients and as partners for medical professionals in their advocacy. Boston Medical Center Launches National Medical Legal Partnership for Children, BUSINESS WIRE (Apr. 10, 2006), available at http://www.csrwire.com/PressRelease.php?id=5368 (last accessed Feb. 11, 2007) [Hereinafter "Zuckerman"] (recognizing that "lawyers and healthcare professionals working together can often prevent illness and can give sick kids a better shot at recovery"). 


\section{b. Collaboration Develops Professionalism}

The appeal of interdisciplinary work largely results from the idea that individuals trained within different academic frameworks each bring something unique to a multitude of problems that transcend disciplinary boundaries. In addition to client gains, from collaboration between and among professional service providers, ${ }^{46}$ the professionals within interdisciplinary engagements often benefit from each other's knowledge, and experience.

\section{i. Interdisciplinary Collaboration Facilitates the Professional Development of Lawyers}

In the clinic ... I learned how important it really is to rely on and work with other people. All of our clients had problems that one lawyer, no matter how gifted, could never solve alone. It took working with professionals in other fields and with each other in order to become helpful. ${ }^{47}$

Lawyers see themselves as helpers much like professionals in the other traditional helping professions. 48 However, the ability of the lawyer to help her client relies directly on her ability fully and correctly to define and to understand the problems of her client. "Only by working with professionals from other disciplines can [she] actually begin to see all the puzzle pieces that make up the complex picture of a problem." 49 Lawyers can not practice in a vacuum. 50

Recognizing the need for lawyers to work with other professionals in order to address client needs leads to opportunities for professional development of the lawyer. Lawyers trained in interdisciplinary environments learn to seek and to implement non-traditional solutions to the "legal" problems presented by their clients. ${ }^{51}$ Similarly, they learn to understand and to coordinate the efforts of multiple professionals in understanding problems and reaching such solutions. 52 The lawyer working on such a team learns not to view the issue and its solution only through the lens of the law, but rather, to understand the value of the contributions from other disciplines. 53 Throughout, the lawyer must respect the boundaries of other professions and

46 See infra Part II.A.2.a (noting the impact on clients).

47 Clinic Law Student (2006) (journal entry, on file with author).

48 See Weinstein, supra note 45, at 306 ("Law, along with medicine and the clergy, should be considered and practiced as the healing professions [sic]."); see also Weinstein, supra note 45 at 324 ("The law is a 'helping' profession.").

49 Id. at 324 (citing James M. Cooper, Towards a New Architecture: Creative Problem Solving and the Evolution of Law, 34 CAL. W. L. REV. 297, 298 (1998)).

50 See Cooper, supra note 50, at 307 ("Law can no longer be practiced in a vacuum.").

51 Particularly in the context of family law, the traditional adversarial system may be detrimental to a client's interests. See, e.g., Clare Huntington, Rights Myopia in Child Welfare Law, 53 UCLA L. REV. 637 (2006).
52 See Weinstein, supra note 45, at 325 ("Lawyers will need to learn to be professionals at organizing, leading, coordinating, inspiring, participating in, and facilitating teams of helpers trained to approach clients' problems from a variety of disciplinary perspectives."); Zuckerman, supra note 46 (describing collaboration as joint effort, not parallel play).

53 See Weinstein, supra note 45, at 327 ("The [traditional lawyer] sees the client's needs as legal needs and then draws upon the expertise of others to the extent required to achieve the legal goal."). Weinstein also writes, "The difference between what frequently occurs now under the name of collaboration and collaboration as viewed by experts on the group process is the teamwork spirit - it is the understanding that no one discipline has the knowledge or skills to provide single-handedly the most effective assistance to the client." Id. at 327-28. 
understand that these may sometimes conflict with the boundaries of legal practice. 54 By understanding the unique boundaries and contributions of various stakeholders addressing the same problem, the lawyer comes closer to achieving her "helping role," for her own client when united with others who share a common purpose. 55

\section{ii. Collaboration Engages Professionals in Broader Societal Issues that Prepare Lawyers for Leadership}

Democracy assumes that the variety of voices and perspectives of our community add to the polity's perspectives, knowledge, and understanding, and thus to the quality of its decision-making and potential for growth. Conversely, isolation and unfamiliarity tend to lead to one-dimensional thinking and stagnation. Lawyers, who make up the majority of the members of Congress and virtually the entire judiciary, are nationally engaged. To be effective, however, legislators, regulators and judges must engage in issues in a multitude of disciplines, including social services, health services, science, economics, engineering, public policy, and others. Exposure to the perspectives, knowledge base, values and strategies of the other disciplines must be considered to improve the quality of their decision making process at every level.

Even outside of law-making activities, all lawyers play a unique role in a society that aims to be governed by a system of just laws that assure everyone of liberty, due process, and equal justice under law, and that support a range of other shared values. Those values also are at the heart of the legal profession ${ }^{56}$ and thus must be part of the socialization that takes place in law school. ${ }^{57}$ We submit that cross-disciplinary experiences in law school, exposing the students to knowledge, perspectives, values, and problem solving approaches of nonlawyers, will, in a sense, both contextualize and "democratize" their understanding of law, the legal process and legal consequences, and so enhance their socialization to the core values of the profession.

\section{iii. Collaboration Offers Reciprocal Value to Other Participants}

The most rewarding aspect of the course from my perspective was being able to use the medical knowledge I had gained to aid children outside of a clinic setting. In theory, I had always known I could eventually apply my knowledge to other fields. Now that I have had the chance to do so, I feel I am better prepared for my future profession as a pediatrician. 58

When the lawyer aligns herself with others who share her purpose, these other participants in the collaborative process receive reciprocal benefits for their involvement. All participants benefit from learning about different perspectives and varied approaches to a problem that each might individually encounter

54 See id. at 327 ("Collaborative work involves more, including communication skills; knowledge about other disciplines, including their range of coverage and limitations; understanding group process and team-building; self- and other-awareness, including the effects of one's behavior on others; and leadership skills."); see also Dale L. Moore, An Interdisciplinary Seminar on Legal Issues in Medicine, $39 \mathrm{~J}$. LEGAL EDUC. 113, 115-16 (1989) (stating that joint efforts promote understanding of another discipline's "rules, beliefs and ethical principles"); Jane Aiken and Stephen Wizner, Promoting Justice Through Interdisciplinary Teaching, Practice and Scholarship, 11 WASH U. J.L. E⿱ POL'Y 63, 66-67 (2003) (arguing that lawyers, especially those working for low-income clients, can learn from the professional skills of social workers); infra Part III (addressing challenges to collaborative arrangements).
55 See Karen L. Tokarz, Introduction, Justice, Ethics, and Interdisciplinary Teaching and Practice, 14 WASH. U. J.L. E) POL'Y 1, 6 (2004) (recognizing the role of interdisciplinary collaboration in bringing together individuals who share the same goals).

56 The American Bar Association defines itself as an organization that is "the national representative of the legal profession, serving the public and the profession by promoting justice, professional excellence, and respect for the law." See American Bar Association, ABA Mission and Association Goals, www.abanet.org/about/goals.html (describing the organization's missions and goals).

57 See Carnegie Report, supra note 2, at 11.

58 Clinic Medical Student (2005) (journal entry, on file with author). 
within her profession. 59 Beyond these advantages, however, the legal profession can offer insight that allows professionals practicing in other disciplines to better meet their professional obligations. ${ }^{60}$ Individuals from a variety of professions will inevitably interface with the legal system at some point during their careers. Interdisciplinary collaborations provide a unique - often the only - opportunity for them to learn about important facets of that system. ${ }^{61}$ Such relationships situate other professionals to provide the best service to their clients by applying the knowledge they are able to absorb from their interaction with other disciplinary practices. The ability of the professional to perform her helping role thus undoubtedly benefits the professional, independently of the benefits it provides to her clients.

\section{c. Exposure to Additional Disciplines During Legal Training Fosters Important Cross-Disciplinary Scholarship}

As academics in legal and other professions collaborate in practice, interdisciplinary scholarship follows. Effective scholarship results from interdisciplinary collaboration that notices existing ties between the law and other disciplines. A growing body of legal literature examining connections between law and psychology seeks to capitalize on unique insights that can be drawn by coupling academics performing the empirical research traditionally reserved to the social sciences with legal theorists who respect the real influence of behavior and emotion on their legal practice. ${ }^{62}$ The growth of empirical research in the legal literature suggests a rising acceptance of this form of scholarship within the legal profession. Moreover, there appears to be a corresponding increase in legal academics conducting empirical work. At the foundation of these scholarly undertakings are relationships. "Some might claim that the only way to actually understand [another discipline] is to do it. ... Another way is to work closely with a colleague who has been trained in [that] discipline." 63 Growth therefore remains possible with continued collaboration between groups of

59 See supra notes 42-46, and accompanying text (pp. 9-10) (recognizing the value of involving multiple disciplines in solving complex problems).

60 See, e.g., Nancy J. Moore, What Doctors Can Learn from Lawyers About Conflicts of Interest, 81 B. U. L. REV. 445, 451 (suggesting the lawyers are more apt at handling narrow conflicts of interest in practice because they have historically had more experience in managing conflicts); see also Paula Allen-Meares, The Interdisciplinary Movement, 34(1) J. SOC. WORK ED. 2, 3 (1998) ("If social workers lack knowledge on the workings of the legal system, they cannot advocate [sic] effectively on a client's behalf, and they may unintentionally promote an adverse outcome."); Zuckerman supra note 46 (explaining that lawyers have necessary and unique skills that can help patients recover). But see infra Part III.B. (commenting that collaborative relationships themselves can also create a source of conflict of interest).

61 See Allen-Meares, supra note 601 (remarking that social workers will almost always have some contact with the legal system during their careers). Allen-Meares also notes the need for increased education on particular aspects of the legal profession, including:

providing information regarding privileged communication; confidentiality and the duty to warn; client access to records; the relationship between legal and ethical issues; practice regulation, malpractice and agency and worker liability; common legal issues arising in practice; the legal rights of various client groups; areas where rights are frequently in conflict; preparation for court appearances of various kinds; and legal advocacy for nonlawyers.

Id. at 3 (quoting Rufus Lynch and Edward Brawley, Social Workers and the Judicial System: Looking for a Better Fit, 10 J. TEACHING IN SOCIAL WORK 77 (1994). Our clinic attempts to address many of these needs in an interdisciplinary setting.

62 See Jeremy A. Blumenthal, Law and Social Science in the Twenty-First Century, 12 S. CAL. INTERDISC. L.J. 1, 6 (2002) ("I focus on two areas in particular: the increased use of research in cognitive psychology on biases and heuristics in decision-making by practitioners of 'behavioral law and economics,' and an increased focus by legal scholars on the role of emotions."). The author notes that this trend generates some controversy. Importantly, however, the author posits that fostering information flow between the professions will resolve much of the disagreement. See id. at 34 ("[W]hat can be done to increase communication, to get the best data and theories in both law and psychology journals into the courtroom, and into policy? At least two suggestions seem helpful. The first, mirroring the interdisciplinary nature of the research undertaken, is to make the researchers' backgrounds and perspectives more strongly interdisciplinary.").

63 Shari Seidman Diamond, Empirical Marine Life in Legal Waters: Clams, Dolphins, and Plankton, 2002 U. ILL. L. REV. 803, 818 (2002). 
thinkers. 64 Training offers ideal opportunities for exchange of ideas across disciplines; these opportunities create relationships that can form the basis of later collaborative scholarship.

\section{d. Legal Education Offers the Best Opportunity to Create Lawyers Who Collaborate}

In most classes, working together is either forbidden or it is just not done because students are competing with one another for a top spot in the curve. . . The clinic was undoubtedly my most difficult and most rewarding experience in law school. It was completely different than any other class. The clinic was collaborative where other classes promote individual competition. The child advocacy work also placed a premium on emotional intelligence that would be inappropriate in other coursework. These differences with the rest of my law school experience made the clinic an invaluable experience for me as a person and as an attorney. ${ }^{65}$

The benefits attaining to interdisciplinary collaboration argue for its increased use in the course of client representation. Nevertheless, professional culture can erect a powerful barrier to effective interdisciplinary collaboration. In addition to concerns about professional boundaries, ${ }^{66}$ socialization within a professional culture can significantly hinder a professional's readiness to collaborate. Only when an individual can remove the narrowing professional lens through which the law school teaches her to view the world to critically evaluate her contribution to a client can she genuinely recognize that a client's problem extends beyond the domain of her profession. 67 Yet, challenging subjective notions of what one's profession is and is not creates uneasiness.

The beginnings of a sense of professional culture occur during legal training. Throughout this experience, students develop perceptions about the legal profession and expectations regarding appropriate responses to issues framed as legal problems.68 These habits of mind are learned implicitly, rather than by overt teaching and learning; yet, they are learned with great power. ${ }^{69}$ When later faced with a difficult situation, these former students, who are now lawyers, will naturally revert to learned perceptions and expectations to predict outcomes and make choices about potential solutions to the situation. ${ }^{70}$ Because "students learn, implicitly, and with powerful emotional stakes, not to ask for support [from] others in solving legal problems," 71 students have traditionally become practicing lawyers without learning how to collaborate. ${ }^{72}$

64 See id. at 817 ("It is no accident that many of the traditionally trained legal academics who have contributed most heavily to the empirical literature have done so through collaboration.")

65 Clinic Law Student (2006) (journal entry, on file with author).

66 See infra Part III (dealing with challenges to multidisciplinary arrangements).

67 See Weinberg and Harding, supra note 44, at 29-34.

68 See Alan M. Lerner, Law $\mathcal{B}$ Lawyering in the Workplace: Building Better Lawyers By Teaching Students To Exercise Critical Judgment as Creative Problem Solvers, 32 AKRON L. REV. 107, 123-25 (1999) (Hereinafter "Lerner, Law 8 Lawyering in the Workplace") (describing a problem-solving course given as a first year elective, in which, after only one semester of law school, every student in the class, when faced with the earliest identification of a potential claim by one person, assumed that the case was already in litigation).
69 Id..; see also Lerner, Using Our Brains, supra note 11, at 679 (arguing that learned mental habits have an enduring effect); Lesnick, Infinity in a Grain of Sand, supra note 16, at 1158 ("[M] uch of what we teach is taught implicitly."); Carnegie Report, supra note 2, at 5 ("The process of enabling students to 'think like lawyers' takes place not only in a compressed period of time but primarily through the medium of a single form of teaching: the case-dialogue method. . . . The consequence is a striking conformity in outlook and habits of thought among legal graduates.").

70 See Lerner, Using Our Brains, supra note 11, at 679 (advancing the idea that law students and lawyers will "downshift" and revert to "tried and true", but often incomplete, approaches to problems under stress).

71 Id. at 698

72 Id. at 698 ("Most law students learn the skills of group process and collaboration only by chance."). 
To create lawyers who are ready for interdisciplinary collaboration, exposure to collaboration must begin during legal training. During law school, students form the foundation of their view of their profession and themselves as professionals. Throughout the law school experience, these future lawyers become emotionally committed to what they believe necessary to becoming lawyers. Therefore, law students are most ready and best suited to adapt their behaviors towards the legal profession as well as other professions with which they might collaborate.

Accepting that collaboration must be taught during professional training, the next logical question is how collaboration should be taught and learned. There are many ways to structure an interdisciplinary experience that may create more or less uneasiness among participants. Advocating also for a greater emphasis on interdisciplinary learning, Weinberg and Harding posit three general models for interdisciplinary education: (1) the 'one discipline studying another discipline model, ${ }^{73}$ (2) the 'representative model'; and (3) the 'team model.'74 In the 'one discipline' model, law students learn about another discipline by studying that discipline in their traditional "home" environment and using their traditional methods of study. In the 'representative model,' mixing occurs at the supervisory level, with professionals from an unrelated discipline sharing their knowledge and experience with another discipline, for example a law professor and an economics professor jointly teaching antitrust law. Finally, in the 'team' model, mixing of disciplines occurs at the level of supervisors and students with a course enrolling students from various disciplines to learn from the knowledge and expertise of faculty from various disciplines. Weinberg and Harding describe this model as "interdisciplinary teams of faculty from diverse disciplines planning and teaching a course enrolled in by students from diverse disciplines and professions," 75 for example a law professor and a psychologist jointly teaching mental health law in a course in which both law and psychology students are enrolled. We take the team model one step further to an 'experientially integrated team' approach. The integration of planning and practice horizontally between clinic participants, as well as vertically between clinic faculty and students, adds a critical layer of implicit learning for students to the more traditional, but solely vertical, interdisciplinary learning approach which occurs in the 'team model'.

We think that this integrated team model permits students to more fully learn both the substantive area of their clinical practice and the process of cross-disciplinary collaboration. Effective educational models for collaboration will address key elements of multidisciplinary collaboration-understanding professionalism, creating opportunities to provide whole client centered services, and engaging students of the various professions in educational endeavors that compel them to recognize the scholarly contributions of another discipline. Clinical law programs are ideally situated to accomplish each goal, and are therefore understandably a common forum for interdisciplinary training in law school.76

\section{B. Designing an Effective Clinical Curriculum}

Since 2002, The University of Pennsylvania Law School has included among its live-client clinical offerings an Interdisciplinary Child Advocacy Clinic, in which the first author has been the Law School's faculty, and

73 Within our institution, the 'one discipline studying another discipline' model is the closest that most students get to an interdisciplinary education. Students may take law school courses taught by an instructor from a different discipline, or may take courses outside of their primary school, which are taught by instructors in whatever school the course is in. Still, in either approach, the student generally studies one discipline; we propose a model that differs from this approach.

74 See Weinberg and Harding, supra note 44, at 37-39.

75 Id. at 37

76 Amsterdam, supra note 3, at 612. 
during one semester of which the second author was a student. We do not argue that this is the only model for interdisciplinary professional education, or that it is, necessarily, the best. For the reasons set forth below, however, we believe that it works well, and satisfies all of the criteria for effective collaboration across disciplines in law, medical, and social work professional education.

\section{Establishing a Child Advocacy Focus}

[E]xperiences in the clinic [] can be summed up in one word - teamwork.... Working on a team in this context is not only helpful, but almost necessary, and this is for two reasons. First of all, it is incredibly helpful to have more than one person available to assist in the investigation portion of the case ... There is another reason why working on a team in this context is so effective, besides the almost inherent efficiency and helpfulness of having more than one person focused on the case. The reason is that, in a situation such as this, where the stakes are so high and the clients are so vulnerable, it is better for everyone involved if the members of the team focus on the aspect of the case where they are the strongest. 77

From antitrust law to workers compensation law, almost every problem a lawyer encounters includes a dimension that extends beyond the boundaries of the legal profession. ${ }^{78}$ In fact, the need to understand subject matter outside of the strict interpretation of the law drives most lawyers towards specialization. While new lawyers may sample from a variety of legal specialties, seasoned practitioners know that it is more efficient to specialize. Why is this so? Because for the client and the lawyer, law does not exist in a vacuum. In every legal problem a lawyer approaches she learns how the law applies to a specific set of facts arising out of the particular client's context; to do so effectively, she must understand those facts, and their relationships to each other, to the clients, and to the context in which they arise. Traditionally, lawyers learn such factual context and relationships from contacts with their clients and with experts in the relevant fields. The lawyer's investment of time and energy in gaining facility with a practice area, and the various players within that practice area, creates an incentive for her to continue practicing within that area. At the same time, the lawyer must and does work with experts from disciplines outside the law such as medicine, social work, economics, mental health, finance, environmental science, etc. Yet, even with the need to rely on the expertise of non-lawyer professionals in practice, most lawyers do not frequently collaborate in the most valuable sense of the word - they see little need, and they have never been taught how to really collaborate. Instead, they alone choose when, how and to what extent to communicate with non-lawyer experts.

Legal clinics in a variety of disciplines are poised to teach collaboration. Law schools throughout the United States house multidisciplinary clinics in environmental law, ${ }^{79}$ estate law, ${ }^{80}$ disability law, ${ }^{81}$ mental health

77 Clinic Law Student (2006) (journal entry, on file with author).

78 See generally Areeda, supra note 3 (acknowledging the prevalence of thought about interdisciplinary work in the 1980 s and earlier).

79 See, e.g., Washington University Law Interdisciplinary Environmental Clinic, http://law.wustl.edu/intenv/ (partnering "student attorneys" with "student consultants" in several graduate studies to provide assistance on environmental and community health concerns) (last visited Jan. 28, 2007).
80 See, e.g., The Camp Center for Estate Planning, University of Florida Law School, http://www.law.ufl.edu/centers/ (offering estate planning services in conjunction with "the Graduate Tax Program and the UF Institute for Learning in Retirement") (last visited Jan. 28, 2007).

81 See, e.g., Disability Rights Law Clinic, American Washington College of Law at American University, http://www.wcl.american.edu/clinical/disability.cfm (representing clients with mental and physical disabilities) (last visited Jan. 28, 2007). 
law, 82 education law, 83 and beyond. Among these options, our choice to create an interdisciplinary child advocacy clinic as the locus of teaching collaboration was guided by several principles:

(1) Law school clinical education offers a unique opportunity to perform a public service;

(2) The stakes in child advocacy cases are tremendously high and demand a rigorous commitment to the whole client, with students engaging both cognitively and emotionally in their work;

(3) Emotional and cognitive engagement fosters habits that can help future lawyers manage the complicated ethical and tactical decisions expected of them in practice; 84

(4) Although engaged in a litigation context, the child advocate spends the majority of her time planning for a child's future; and

(5) Lawyers involved in planning for their clients' future have a greater need for, and are therefore more likely to engage in, collaboration than lawyers who litigate past matters. ${ }^{85}$

Starting from these principles, we decided to focus on the representation of children involved in the dependency system in Philadelphia. There are, of course, countless worthy endeavors that benefit the public interest, and a number of them specifically involve advocacy for children. Still, it is undeniable that advocacy for abused and neglected children is one of the areas of greatest need. It is also undeniable that even in such clearly legal proceedings, interdisciplinary involvement is critical. 86

\section{Who to Involve: Identifying Key Players in Child Advocacy}

The first step in creating an effective interdisciplinary collaboration is to identify the interested parties. In the child advocate's ideal world, she would have countless resources available to help her client - lawyers, social workers, educators, mental health professionals, pediatricians, and policy makers all in some way influence the care and disposition of children in the dependency system. Aspiring to truly serve "the best interests of the child" might require the involvement of professionals in each of these disciplines to

82 See, e.g., Mental Health Law Clinic, University of Virginia School of Law, http://www.law.virginia.edu/html/ academics/clinics.htm\#11 (permitting students to gain experience representing mentally ill or mentally disabled clients in negotiations, administrative hearings and court proceedings) (last visited Jan. 28, 2007).

83 See e.g., Children's Education Law Clinic, Duke Law School, http://www.law.duke.edu/magazine/2006spring/ features/educationlawclinic.html (focusing law students on advocacy in school-related special education and disciplinary matters) (last visited Jan. 28, 2007).

84 See supra notes 11 and 17 and accompanying text (describing the importance of considering how the brain processes and implements new information when designing educational programs).

85 Winning an adversarial encounter for a client concerning a fact pattern that happened in the past, and the legal implications of these facts, may, but need not, require consideration of the longer-term implications for the client in non-legal areas. Whenever planning for the future is at issue, however, the client's relationships with others are relevant, perhaps critical. But the process for building and maintaining relationships is not necessarily taught or learned in traditional legal curricula.

86 See, e.g., PEW COMMISSION ON CHILDREN IN FOSTER CARE, FOSTERING THE FUTURE: SAFETY, PERMANENCE AND WELL-BEING FOR CHILDREN IN FOSTER CARE, 17-18, 40-41 (2004) (recommending that judges and attorneys who are involved in child welfare cases receive interdisciplinary training in order to be able to understand and effectively respond to issues of child abuse and neglect). Child welfare systems are beginning to recognize the value of interdisciplinary work. For example, as a result of the consent decree in Kenny A. v. Purdue, No. 1:02 CV 1686 - MHS (ND Ga. 2005), the Fulton Workload Study asked our clinic to review the ABA/NACC Standards for attorneys representing children in Juvenile Court, which are the established standards for the Office of Child Advocate created pursuant to the consent decree, and identifying where and how social work partners for the lawyers can improve the quality of legal representation assigned to lawyers for children. The review was conducted by the first author and our clinic Social Work Supervisor, Diane Smith-Hoban, MSW. Other areas that demand interdisciplinary attention include domestic violence, disability law, elder law, environmental law, housing, Indian land claims, mental health law, etc. 
effectively advocate for a child. But this aspirational world is different from the one in which we - as lawyers, social workers, educators, mental health professionals, pediatricians, and policy makers individually conduct our every day practices for the benefit of children.

As an initial matter, resource limitations, both financial and otherwise, inevitably force choices about who to include when designing a clinic with an interdisciplinary focus. Financial considerations will undoubtedly limit the number of professionals a single clinical program can include. Beyond this, however, as clinical educators, we ought to consider the pedagogical value that additional faculty will offer. We built a clinical model that was useful, manageable for both faculty and students, and that would not interfere with providing very high quality services to the clients. Our goal was to include a faculty diverse enough that students could benefit from learning about the ways that different professionals think about the problems faced by their clients. However, we also wanted to create consistency in teaching, such that students learned enough from a core faculty member in their respective fields to understand how they as professional students could begin to work effectively for their clients. Additionally, as a practical matter, with the addition of each faculty member, we would decrease the possibility that all of the faculty would be present at a given seminar. This cross-disciplinary interaction and discussion is precisely what we sought for clinic students. Because students would be the "front line" service providers, we had to avoid so inundating them with material from outside their home discipline that they would be unable to integrate it into a case plan and execute that plan in the time frames provided by the cases and the academic calendar. The combination of faculty members we arrived at has facilitated these goals.

We ultimately designed a clinic supervised by a lawyer, a pediatrician with expertise in medical issues of child maltreatment, and a social worker with extensive experience working with children and families in the child welfare system. This combination ensured that our students would have access to professionals who had encountered and cared for children with issues similar to those encountered by our clients. Through the combined experience of these supervisors, our students are able to discern and respond to legal, medical, educational, and social concerns in their client's cases. Concurrently, we use consultation with other professions both in the seminar and as needed in case work to ensure that we can address the full spectrum of our client's needs. 87

Students in the clinic gain more than exposure to interdisciplinary teachers. We envisioned a clinical model that would promote collaboration at every level. Law students are joined by a social work student and a medical student to create child advocacy teams for each case. At every step of the way, then, students are able to discuss, plan, challenge, and create solutions with other students who bring their distinct educational training and perspective to bear on a case. While the students each come with a different approach to clients or patients, in another sense they are all "naïve," at least in the other disciplines, and this facilitates tremendous learning opportunities. The cases belong to each of the students; each student's input guides the planning and execution of each intervention. They need each other. At a fundamental level, this need and availability encourages learning the essential skills of collaboration by doing. 88

87 Consultation and teaching by additional professionals who play a role in the advocacy for children in the dependency system, including mental health professionals and educators, provides us with more detailed knowledge of issues that are detected by our law, social work and medical students and confirmed by our attorney, social work, and pediatric faculty who provide ongoing supervision of students. See infra Part II.C (outlining the didactic portion of the seminar); see also Weinberg and Harding, supra note 44, and accompanying text (referring to this type of crossdisciplinary instruction as the representative model).

88 See Lerner, Using Our Brains, supra note 11, at 665 (learning that has a strong emotional content creates strong neural connections and sources for recall, thus making it lastingly effective and useful). 


\section{What to Teach}

While the primary mechanism through which students in the clinic gain experience is fieldwork, ${ }^{89}$ students also meet for didactic seminars twice weekly. Through these sessions, students learn the value of involving numerous disciplines while planning for their clients. The seminar component integrates three distinct modes of instruction: specific subject-matter expertise, skills-based teaching, and personal and professional reflection. All clinic faculty and students attend each seminar meeting and participate both in the teaching and discussion on each topic. ${ }^{90}$ Thus, students regularly receive instruction in the knowledge base, strategies and values of three professions: social work, law, and medicine, focused on their application within the child welfare system. Additionally, we invite guest speakers with particular expertise in mental health, adolescent health, and early childhood development and intervention to supplement the more generalized knowledge and experience of the core faculty. The variety of instructors ensures that students receive exposure to various ways in which the same problem might be addressed depending on where a client or patient first interfaces with a professional working in the child welfare system. It also ensures that law students at least implicitly recognize that their client's "legal" problem can present in a variety of settings, and benefit from a variety of approaches.

a. Keeping your eye on the ball: Expanding perspectives, understanding oneself, limiting judgment of others.

Child advocacy readily lends itself to strong emotions, and to making harsh judgments about parents, child protection workers, service providers, other advocates, and "the system," as well. After all, these are innocent children; we are their advocates and protectors, and they need us because the other adults and the system have failed to provide what our clients need! We do not seek to prevent or eliminate this emotional identification with our clients. However, we do work hard to keep our students focused on the goals for the clients, and to understand that all of those other folks, beginning with our clients' parents, are more likely to provide the short-term and long-term needs of our clients that we are. Indeed, an essential aspect of our work is to get those others to do theirs. Important as they are, the only services that we can provide for our clients are counseling and advocacy. We know, and our students need to learn, that although we need to be ready, willing and able to employ our most effective litigation tools, cooperation may be more likely to get the services our clients need in the short run, while retaining the relationships they need in the long run, than will a purely adversarial stance.

At the same time, especially with children of middle school and high school age, counseling them about their situation, their goals, their options, the relationship between their present choices and behaviors and their future, etc., is a critical aspect of our work as their advocates. Counseling a disappointed, sad, frustrated, victimized, angry, often troubled youth is an emotionally challenging experience, especially for students. Often they have had experiences in their own lives that are returned to consciousness when they are engrossed in their clients' situations. Alternatively, they might find that their clients' experiences seem completely foreign and beyond their comprehension. In either case, emotions run high and strongly impact their role as counselors and advocates.

This emotional "heat" and tension provides both the necessity and the opportunity to begin teaching our students about the role that their own values and emotions play in their perception and response to

89 See infra II.B.4 (describing the clinic fieldwork component).

90 Our clinic is fortunate to have all participating schools located in close proximity. While all campuses will not have this arrangement, the possibility for interdisciplinary learning and collaboration remains. See generally, e.g.,
Paula E. Berg, Using Distance Learning to Enhance CrossListed Interdisciplinary Law School Courses, 29 RUTGERS COMPUTER \&ु TECH. L.J. 33 (2003) (suggesting alternative mechanisms by which crossdisciplinary training might be accomplished). 
situations which arise in their cases, and in counseling our clients. ${ }^{91}$ We address these issues beginning with the first class, and incorporate them pervasively throughout the semester in both didactic classes and in case discussions, culminating in a class on counseling alternatively known as "Self Awareness In Advocacy." Because this topic is so foreign to traditional legal education, 92 and yet so important, we try to mix the serious discussion with exercises that are fun for the students to assure maximum engagement.

\section{b. Broad-based Subject Matter Knowledge}

Students begin their experience in the seminar component by directly confronting the potential overlap of various disciplines which plan for the future of children in the dependency system. In the first class, before any statutes or cases are assigned, we ask them to read material that both discusses the nature and harm to children resulting from abuse and neglect, ${ }^{93}$ and critiques of the child welfare system. 94 We then give them problems taken from actual cases to discuss whether they think there has been abuse or neglect, and what, if anything, the state should do in response. They explore specifically how differences in the legal and medical definitions of abuse and neglect affect how these professionals perceive and respond to the problem. By framing the class in this way, students learn at the start to think about the fact that they come to the issues with values and expectations, not as blank tablets, and that they need to consider these "legal problems" as "medical problems," "social problems" or even through other lenses. Through this discussion, students also start to gain the substantive knowledge they will apply to their cases. In the remaining seminar sessions, students gain exposure to several aspects of the dependency system, including the process for reporting and responding to allegations of abuse and neglect, the legal framework affecting children who are involved in the welfare system, interventions available to assist children and families in the welfare system, and the interplay between the rights of children and parents in dependency proceedings. This somewhat in-depth instruction in child welfare law prepares students to competently represent their clients. Students additionally receive substantive instruction from professionals involved in providing nonlegal services to their clients. For example, clinic students spend one session with the clinic social worker to discuss generally the wide range of community resources applicable to children and families in the child welfare system, and the case-specific indicators for different services. A child development expert describes early childhood development and discusses early intervention programs available to children at high risk for future developmental delays. A mental health professional provides insight into the assessment and evaluation of mental health issues in students' cases.

\section{c. Skills-Based Instruction}

A skills-based component complements the substantive child welfare topics and includes sessions dedicated to skills traditionally required of advocates within the legal system. The skills sessions begin with general case planning considerations and then move to a more detailed examination of individual skills essential to successful case management. Students first learn the basics of legal interviewing; these skills are then refined through sessions specifically addressing developmentally appropriate techniques for communicating with child victims of physical and sexual abuse. The experience of a specialist in adolescent medicine contributes to a separate session considering communication with adolescent clients. Students learn further about preparing cases and examining witnesses through a simulation in which law students represent either

91 See Lerner, , supra, note 11, at 665 (discussing how our emotions and values affect our perceptions and judgments).

92 See discussion at pp. 7-12, supra.

93 Vincent J. Felitti, et al, Relationship of Childhood Abuse and Household Dysfunction to Many of the Leading
Causes of Death in Adults, 14 AM. J. PREV. MED. 245 (1998).

94 DOROTHY ROBERTS, SHATTERED BONDS: THE COLOR OF CHILD WELFARE (Basic Civitas Books, 2001). 
the parent or the state in a proceeding in which a parent, opposed by the state, seeks to have her name removed from the state registry of care givers who have abused or neglected children in their care. ${ }^{95}$ Each student conducts a direct and a cross examination of an expert medical witness and social worker fact witness. The experience provides students with an opportunity to distinguish the types of inquiries that can be directed at these two types of witnesses. It also encourages law students to think about how best to formulate questions that will help experts communicate technical information in a manner understandable to those who must rely on it for judicial decision making. The social work and medical students who serve as witnesses also gain insight from the experience. They spend time with the law students prior to testifying and learn how to effectively communicate their knowledge to a judge and jury. As preparation for this experience, students spend time in seminar sessions thinking about the differences in language and communication techniques that different professionals bring to a courtroom. These sessions highlight the crucial importance for the lawyer to learn effective ways to communicate with professionals from various disciplines in order to carry out even one of the most basic courtroom lawyering tasks. ${ }^{96}$

\section{d. Personal and Professional Reflection: from Micro to Macro}

The bridge connecting the case work experience and the subject matter seminars is personal and professional reflection. Throughout the semester, all students reflect on their personal involvement in their cases through weekly case rounds. These rounds, fashioned similarly to the rounds one might encounter on a hospital floor, require students to present a case and then invite discussion among all of the clinic participants in resolving difficult situations. Students sometimes face insurmountable challenges in their cases; however, the most rewarding successes often come from suggestions raised in the cross-disciplinary discussion that occurs during case rounds. Here, there are two levels of collaboration at play, that between and among student members of each advocacy team, and that between and among the faculty members from the various disciplines. The combination of the experience of the faculty and the capacity for interdisciplinary work within individual teams provides for unique and effective solutions for clients. While each student is assigned only two or three cases, their opportunity to consider and reflect on the variety of challenges faced by children and families caught up in the child welfare system is multiplied by the shared experiences of their colleagues in these case rounds and in daily conversations in the student work rooms. ${ }^{97}$

The focus on the students' fieldwork in terms of providing service for their individual clients/patients is critical for the students' learning. However, towards the end of the semester all students are asked to take a step back from the "firing line," put their professional experiences and role into a larger context, and to consider their efforts in terms of policy proposals that address how to change system-wide problems they encounter in their casework. This exposure encourages reflection about how the work of different disciplines comes together at many levels to create the environment in which each professional practices.

95 We include the simulation in the course to ensure that all law students learn the skills of preparing and examining both fact and expert witnesses, and to ensure that medical students and social work students involved in the clinic understand their potential influence when called to act as a witness in their professional capacity. Some students will gain this experience through their case work. However, because cases will inconsistently require expert testimony, the simulation guarantees exposure for all students.

96 We employ a variety of media to introduce potential communication problems between lawyers and witnesses. Students observe video of lawyers conducting interviews of expert witnesses. They also participate in a exercise using children's building blocks in which one student (the "witness") constructs a structure and another student (the "lawyer") must then lead a third party who cannot see it (the "fact finder") to recreate the structure from information obtained through questioning by the "lawyer" of the "witness". The exercise demonstrates in a tangible way that only by effective communication can the information in one person's mind transfer an accurate picture of a set of facts into another person's mind.

97 In addition, the students have opportunities for reflection through weekly meetings with their supervisors, and journaling. See parts 4. b and c., infra, pp. 23-24. 
At the same time, it highlights the complexity of the "system" and the breadth of cross-disciplinary considerations that need to be addressed in forging lasting improvement.

\section{A Cross-Disciplinary Fieldwork Experience}

Case rounds are in a sense the bridge between the didactic and experiential components of the child advocacy clinic. Outside of the seminar sessions, students spend the majority of their time involved in direct case work for their clients. This fieldwork component creates the greatest opportunity for collaborative work.

Our clinic receives case appointments through the Family Division of the Philadelphia Court of Common Pleas, the court of general jurisdiction of first instance in Pennsylvania. We receive our appointment at the time a dependency petition is filed, or when a hearing on an emergency restraining order is about to be heard. ${ }^{98}$ Although we recognize that cases vary in their complexity, ${ }^{99}$ the focus of our clinic remains on teaching the process of case planning and management, creative problem solving for our clients, and collaboration skills; we believe every case provides challenges in each of these areas. Because we expect all students to complete a full-case work up whenever they receive a case in preparation for their client's court hearing, we do not restrict the type of cases we are assigned. Once accepted, each case is assigned to a student team.

Student teams are comprised of a law student, a social work student and a medical student. Each law student is assigned a caseload of two or three cases, permitting her to represent on average two to four children in dependency proceedings. Most cases involve social work and medical issues. One social work student and usually one medical student handle these issues on cases. All aspects of case management are carried out using the team approach. Students therefore gain an interdisciplinary experience most directly through their case work. Journaling and cross-disciplinary supervision reinforces the lessons learned through fieldwork. 100

\section{a. Case Investigation and Management Draws on the Various Professions}

Students begin their casework with a multidisciplinary framework in mind. Understanding that they need information from a variety of individuals involved in their client's lives in order to provide the most effective client representation, students begin by information-gathering. During the initial stages of this process, client-teams will make visits to a client's home and, if applicable, to a client's school. Consider one law student's impression of her first home visit.

The visit that scares me is the visit to Mom's home. For some reason, I have a picture of the place in my head that I can't seem to get rid of, and the thought of going there is slightly terrifying. Not to sound like I

98 When a dependency petition is filed in the court, a hearing will follow within ten days to determine whether the child is dependent, and if so, whether supervision in the home or removal and placement is necessary to assure the child's health, safety and well-being. Experience has demonstrated that the allegations of the petition are frequently incomplete or inaccurate. Therefore, assignment of a case calls on the advocacy team to investigate and develop a preliminary case plan and hearing plan within a relatively short time. Thus, every dependency petition will create opportunities for a case investigation and court exposure for students.

99 The only conditions we place on cases that we will accept are: (1) timing: we prefer to have no case go to a hearing during the first two weeks of the semester, and to have all of the cases assigned before the mid-point of the semester so that the students have ample opportunity to work on them. (2) We prefer to have cases with three or fewer children because we want each law student to handle two cases as the only law student on the case and we have found that for inexperienced students, families with more than three children involved are so complex as to jeopardize their ability to provide high-quality representation. The level of complexity and propensity for future learning associated with cases does factor into our decision-making regarding case retention at the end of the semester. See infra II.B.4.a (outlining how students make decisions regarding end-ofsemester case disposition).

100 See discussion infra, pp. 37-40. 
believe in auras and vibes and other new-age ridiculousness, but I think I'm scared of the house. I think it was [someone] saying that the walls of the home are punched out that did it. Because I couldn't think about the walls being punched out without imagining what would have happened that would result in the walls being punched out. And now I have this scene in my head that involves a very angry person yelling and punching out walls and generally being out of control. And the fact that I know that there are two young kids in this house right this second as I type this bothers me to no end. 101

While the law student has an appropriate visceral reaction to the situation she encountered - one of many situations that can make us painfully aware of the vulnerability of our young clients - this initial emotional reaction sets up a unique opportunity to learn. Her powerful response stimulates a strong emotional memory for this occurrence. 102 Although the law student may have felt slightly overwhelmed by her own reaction to the situation in her client's life, and as a result, unable to completely evaluate the home situation, the social worker's experience in communication and assessment of family dynamics makes possible a more complete and informed evaluation of the child's living and school situations. ${ }^{103}$ When she later recalls this experience, she will be more likely to remember how the interdisciplinary framework provided strong support to ensure that she was able to perform at a high level for her client. Thus, while the law student may specifically learn from this experience the importance of collaborative work, our client's needs are also fully met by utilizing the social worker's particular readiness to assess and respond to the situation appropriately. 104

In addition to conducting home visits, our students obtain and review the file from the child protective services agency, and our client's school and medical records. Our social worker again plays an important role by following up on deficiencies noted in the school record and helping students better understand the agency records. The role of the medical student-law student collaboration, however, becomes particularly relevant at this stage. The medical student facilitates a basic understanding of the client's medical, developmental and mental health record, but perhaps more importantly in the cases we face, where neglect is common, the medical student's knowledge of appropriate preventive and reactive care helps them to determine whether the child has had appropriate health care, and, if not, what is needed and with what level of urgency to ensure the child's well-being. This knowledge directly impacts the law student's assessment of the adequacy of parenting in making a disposition recommendation at a court hearing; it also

101 Clinic Law Student (2003) (journal entry, on file with author).

102 See Lerner, Using Our Brains, supra note 11, at 665 (describing how the brain creates memories, from patterns of neuronal connections comprised of all of the elements of the experience, and that the emotional aspect is a particularly powerful facet of most experiences).

103 Students have directly acknowledged the necessity of a multidisciplinary approach to gathering information. One law student commented:

When we visited [our clients] at their schools, I had no idea how to explain to them what was going on, how to introduce myself, or even so much how to relate to them on each of their levels. Thankfully, I was accompanied by [our social work student], whose training in social work has included a good deal of direct contact with children of various ages who are in unstable home environments.

Clinic Law Student (2005) (journal entry, on file with author).

104 Students are always accompanied on home visits by at least one supervisor. 
aids the student in making requests for the court to order needed interventions. 105

The knowledge that a medical student or social worker is able to obtain can significantly impact the direction and management of a case. In some cases, the medical student becomes instrumental in formulating a plan for our client after a decision regarding adjudication has been made. ${ }^{106}$ Clients who are adjudicated dependent secondary to neglect often have a number of medical problems that require attention. ${ }^{107}$ However, our law students consistently report difficulty in communicating with professionals who are unaccustomed to, or fearful of talking with lawyers. One student questioned why this is so: "Why is it so hard to schedule doctor's appointments? Why is it so hard to get people to help you? Why, only after [our medical student] said she had a pager, did we get anywhere?"108 The answer lies in one of the original motivations for designing our clinic. Because doctors and lawyers are educated in a manner which tends to isolate them from the other profession, neither learns how to trust or communicate comfortably with members of the other discipline - and so they don't. Our clinic addresses that divide by putting the students together in close, mutually dependent, but safe environments with experienced supervisors and, only in that context, making available to our clients the resources of both disciplines.

Although the cases themselves may continue well beyond a year or even two years, ${ }^{109}$ the educational value of these cases is not linear. The majority of the planning and decision making done by advocates in child welfare cases takes place either in the first six months after the case comes to court, or much later when decisions with respect to reunification or perhaps termination of parental rights must be made during permanency planning. To enable us to take new cases at the beginning of each semester for our new students, we arranged, with the court's permission, to transfer some or all of our cases to a local non profit child advocacy

105 The legal determination of dependency rests at least partially on whether the child's health is at risk as a result of a parent's action or inaction. See 42 Pa. C.S.A. $\$ 6302$ (defining a dependent child as one who "(1) is without proper parental care or control . . . A determination that there is lack of proper parental care or control may be based upon evidence of conduct by the parent ... that places the health, safety or welfare of the child at risk....") (emphasis added). The medical student's knowledge permits her to assess not only problems documented in the medical record, but additionally, to know what should be but is not in the record, which a law student or lawyer alone would not be able to discern. Because the law defines dependency in this way, this kind of determination is necessary in all cases in which a dependency petition has been filed. The consideration that all cases will require some medical assessment regarding the health of the child plays a role in the decision that an effective collaboration in this area will involve a medical professional. See supra Part II.B (discussing the factors prompting a choice of which professionals to involve in a collaboration). We discussed at length above that lawyers may want to involve other professionals in their work with their clients because the problem itself may be only partially legal in nature, but also a social problem, medical problem, etc. When designing a collaboration in any field of law, considerable attention should arguably also be paid to whether the legal aspects of the case itself require the expertise of another profession.

106 Our clinic handled one case in which children were temporarily removed from their mother's care because her noncompliance with ordered medication for a communicable disease put her children at risk for acquiring that disease. The medical student's ability to understand the significance of apparently conflicting medical reports and obtain the cooperation of a doctor from the Department of Public Health made a critical difference in the outcome of the case, and in the health of the children (case details on file with author).

107 Even where the primary dependency issue is physical abuse, truancy, or sexual abuse, a large percentage of the cases involve some medical issue. Numerous studies have documented the significantly disproportionate health care needs of children entering foster care or already in foster care. See, e.g., R. Chernoff et. al. Assessing the Health Status of Children Entering Foster Care, 93 PEDIATRICS 594 (1994).

108 Clinic Law Student (2006) (journal entry, on file with author).

109 The Adoption and Safe Families Act (ASFA), passed in 1997, requires that all children in care have a permanency plan in place within twelve months of placement. When the plan is reunification and a child has been in care consecutively for fifteen of the past twenty-two months, ASFA requires that the case goal change from reunification to termination of parental rights and adoption unless one of several discrete exceptions is met. The change in policy reflects recognition that for a child in care, long-term stability requires a permanent living situation. See Adoption and Safe Families Act, Pub. L. 105-89 (1997). 
organization at the end of each school term. ${ }^{110}$ This process itself provides yet another educational opportunity. As each semester draws to a close, the clinic must decide which cases to retain for the following semester and which to transfer to the outside agency. All students prepare memoranda detailing their perspective on whether to keep their cases. During an extended case rounds session, 111 each student is required to recommend whether we should retain the case or transfer it to The Support Center, and then defend that recommendation. Factors in each discipline play a role in the final decision. As educators, we pay attention to the educational value of keeping the case. We also, however, take into account any pressing legal, social, or medical issues. To the extent that our relationship with the client will facilitate addressing any of these needs, we will consider keeping the case. Especially when the clients are pre-teen or adolescents with whom we have developed close relationships, that relationship, set against the background of the client's maltreatment history, requires that we consider the possible impact of seeming to abandon the child at the semester's end. This exercise permits students to consider their duties of loyalty and competence to their clients, taking into account the particular expertise afforded by the clinic's multidisciplinary resources. When the client is one with whom the student has developed a strong bond, or the client has suffered particularly severe maltreatment, it is common for the student to want us to keep the case so that she can feel comfortable with the quality of advocacy that "her" client will get. These expressions of students' connections with, loyalty to and responsibility for clients demonstrate as little else can the emotional power of the student's experience, and show that they have begun to internalize the highest meaning of being a zealous advocate for one's client.

\section{b. Journaling Reinforces the Multidisciplinary Experience}

Especially in work that is regularly intellectually challenging and emotionally draining, it is important to be able to identify and to accommodate our reactions. . . . Doing this is easier because, in the midst of a professional educational culture that prizes individual accomplishment, in the context of our casework, we don't have to do it alone. 112

Throughout their fieldwork, students comment on their reactions to their cases in weekly journals. Journaling serves two primary purposes. First, journaling creates a unique opportunity for students to manage reactions to the work that they are doing - work which is highly stressful, time demanding, mentally challenging, and emotionally draining. ${ }^{113}$ Describing these very powerful emotions through writing permits students to better contemplate their feelings and responses. These emotional reactions, so often overlooked in traditional teaching models, in fact help to solidify the "habits of mind" that these to-be lawyers will revert to in their future practice. 114 Students review their journals, and therefore their reactions, with clinic faculty during weekly supervisory meetings. This review provides another opportunity for learning from the experience and reinforces the student's impression of the experience. ${ }^{115}$

110 The agency - The Support Center for Child Advocates has been in business for thirty years and is very highly respected for the quality of its advocacy for children.

111 See supra Part II.B.3 (outlining the case rounds component of the seminar).

112 Clinic Law Student (2006) (journal entry, on file with author).

113 Journaling has been described as an important tool in professional development. See, e.g., JOHN C. BEAN, ENGAGING IDEAS: THE PROFESSOR'S GUIDE TO INTEGRATING WRITING CRITICAL THINKING, AND ACTIVE LEARNING IN THE CLASSROOM 106-109 (2001); James R. Elkins,
Writing Our Lives: Making Introspective Writing a Part of Legal Education, 29 WILLAMETTE L. REV. 45 (1993).

114 See Lerner, Using our Brains, supra note 11, at 655, 671 (noting the importance of emotional thought in forming habits of mind).

115 Originally, faculty included journaling as a tool for the faculty to be able to assess whether students were having difficulty with the emotional experiences of their casework and intervene where necessary. That has happened a number of times. Yet, it appears the journaling itself frequently provides the students with an opportunity to both express and engage their emotions in constructive ways. See text accompanying note 113, supra. 
Second, journaling motivates students to reflect systematically on their casework. Student journals detail the most complicated aspects of cases and outline potential approaches to resolving these problems. Often, we find students commenting on the importance of involving multiple players in these approaches. Students consistently reveal a deep appreciation for the interdisciplinary nature of their fieldwork in their writings.

One of the greatest benefits of collaborative work is that it allows us to be able to need and give different things at different times, without sacrificing the needs of our clients. The different knowledge and skills that the various professionals bring to the clinic ... first helps us all to be able to better deal with the sometimes emotionally challenging aspects of our cases, by creating an internal support network. . . Equally important, however, is that the client benefits from having more than one person fully aware of the status of their case, and ready to step into the role of supporting the client whenever necessary. 116

Through these statements, students recognize the implicit barriers to more productive cross-disciplinary collaborations and how the interdisciplinary approach begins to overcome these barriers. Moreover, students from the various disciplines note the same advantages to the interdisciplinary structure; almost all of these entries focus on the discrete benefits this structure affords to our clients. ${ }^{117}$ The exercise of putting their thoughts into writing ensures that students give explicit attention to the importance of the collaborative effort, further raising students' acknowledgement of this idea from subconscious to conscious awareness.

\section{c. Cross-Disciplinary Supervision Balances Student Autonomy to Ensure Multidisciplinary Thought}

Supervision is the final mechanism through which the clinic creates a multidisciplinary experience. All clinic students have weekly supervisory meetings with a member of the clinic faculty. In addition to these meetings, any significant case development usually motivates an interim meeting convening clinic faculty and students involved in the particular case. During these issue-focused meetings, like case rounds, clinic faculty first ask each student to rehearse the problem as they see it, then to suggest potential solutions. Early in the semester, most students articulate a problem and propose a solution from the experience of their home discipline. ${ }^{118}$ Thus, a law student is most likely to suggest a legal solution, a social work student a social one, and so on. Because the different disciplines are brought together in these meetings, the

116 Clinic Law Student (2006) (journal entry, on file with author).

117 One medical student commented on the considerable influence her expertise played in making legal determinations about a case.

Although I often am involved in a lot of "behind the scenes" work in many of these cases, I felt that my participation in the pre-hearing conference actually made a difference. . . . I just wanted everyone to hear the medical truth according to the children's physician. When I was finally able to speak, I was so emotional. . . . I couldn't bear to imagine these children sick and wasting away because of their mother's inability to adhere to medical recommendations. ... [T] his was also a prime example of the true interdisciplinary nature of this clinic. I was able to obtain medical information that may have been more difficult to "digest" for those not involved in the health professions. [Our law student] was able to focus on the legal guidelines, the theory of the case, and our argument. [Our social worker] did her part to contact teachers, social workers, and other people involved in the case, carefully documenting her findings. It was satisfying to know that our work made a difference in children's lives. Clinic Medical Student (2005) (journal entry, on file with author)

118 See Lerner, Using Our Brains, supra note 11, at 679 (describing this "downshifting" effect as common during periods of stress); Clinic Medical Student (2005) (journal entry, on file with author) (commenting on the struggle to approach a case problem from her medical background). The student wrote:

At the same time, however, I was struggling with a competing issue separate from the legal argument. Legally speaking, there was no evidence that the [parent's alleged behavior] had ever placed [our client] in danger. Medically speaking, my as of yet immature medical instinct told me that living with [this parent would not be] an ideal situation for a child. I could also venture to guess that there exists research data on the risk of child abuse by the presence of [such a parent] in the home. Yet, I had to remember that we were in a legal forum abiding by legal procedures and available evidence. . . . Had I been on the other side of the argument, I may have pursued the corroborating medical evidence. 
perspectives of the various disciplines are brought to bear on the case through this approach. Students listen to concrete and often widely different suggestions from other clinic students, and we find consistently that as the semester moves on each student is more likely to approach a problem already contemplating issues which earlier would have been raised only by a team member from another discipline. Teaching this habit of mind through "real-life" concrete problems in cases relevant to the students involved provides the best opportunity for long-term retention. ${ }^{119}$ Faculty members from the various disciplines, however,closely supervise these meetings to make certain that client interests are consistently met.

\section{Promoting Collaborative Scholarship}

The interdisciplinary nature of the clinic encourages rich scholarly collaborations, both in studying the impact of our clinical design, as well as in substantive issues in child welfare law. Since the clinic began operating, collaboration with the School of Social Policy and Practice has made possible two evaluations of the clinic's impact in providing service, and on the professional development of attorneys who complete the clinic during their legal training. ${ }^{120}$ This arrangement capitalizes on the social science research capabilities inherent to social work training, permitting the clinic to objectively evaluate its operation in terms of the empirical findings shown in this research. ${ }^{121}$ The study also created a methodology for evaluating the work of child advocacy programs outside of our individual clinic, establishing a basis for evaluation and improvement on child advocacy work in general. ${ }^{122}$ In addition to these activities, faculty and students in the clinic have been involved in other scholarly work. Scholarly endeavors between clinic students and faculty members of the same profession provide examples of intradisciplinary collaboration; faculty arrangements with members outside of the legal discipline demonstrate interdisciplinary approaches. Examples of scholarship which have emerged from this clinic include an analysis of the clinic's cases presently underway to ascertain whether there are early case indicators of long-term problems in neglect cases, a study of the legal standards and procedures for permitting proper investigation of reports of child maltreatment in the face of uncooperative caregivers, proposals for a national study of the administration of psychotropic medication to children in foster care, and a study of the quality of child advocacy in dependency cases in Pennsylvania. Already completed are studies of the efficacy of pre-hearing conferences with trained mediators in dependency court, performed at the request of the Administrative Judge of Family Court, and an analysis of the Pennsylvania law and practice with regard to mandating mental health evaluations for caregivers in dependency cases, performed at the request of the Family Court's Court Improvement Project. ${ }^{123}$

119 See Lerner, Using Our Brains, supra note 11, at 695 (concluding that problem-based learning based upon reallife situations is particularly effective in creating retained and re-usable knowledge).

120 See Robin M. Mekonnen and Melissa E. Dichter, Evaluation of an Interdisciplinary Child Advocacy Clinic (unpublished paper/publication forthcoming, draft on file with author) (evaluating the clinic's ability to create positive outcomes for clients, develop students academically and professionally, and generate positive responses from other key stakeholders in child welfare proceedings); see also Celina A. Wollak, Penn Law School Child Advocacy Clinic: Evaluating the Impact of Participation on the
Professional Lives of Former Law Students, University of Pennsylvania School of Social Policy and Practice (Apr. 28, 2006) (on file with authors).

121 See supra note 14 and accompanying text (recognizing the benefit of using non-legal ideas and methodologies to influence legal scholarship).

122 See generally Mekonnen and Dichter supra note 121 (discussing future directions for building upon their initial study).

123 Material relating to each collaboration is on file with the authors. See also supra note 121 (discussing an additional clinic-related collaboration). 


\section{CHALLENGES TO DEVELOPING MULTIDISCIPLINARY TEACHING AND PRACTICE}

Despite the tremendous benefits that accompany interdisciplinary collaboration, participants in the collaboration face unique challenges. Careful planning and commitment by complementary professionals, who are respectful of their partners and their partners' professions, are essential to success.

\section{A Choosing Partners}

\section{Disciplines that are Complementary.}

When we started to think about creating an interdisciplinary clinic, our first thought was to ask with whom we might collaborate. The decision required some preliminary understanding of what our subject matter and practice strengths and weaknesses were. As an experienced litigator, the first author knew that, because lawyers are always learning new legal subject matters in order to litigate a particular case, merely not having expertise in a particular litigation-based area did not preclude collaborating in that subject matter area. 124

In fact, our first effort was to develop collaboration around legal issues related to domestic violence with a friend who is a physician on the faculty of the University of Pennsylvania's School of Medicine and runs a clinic for abused women. The law and practice relevant to domestic violence seemed learnable. As it turned out, that collaboration lacked the joint-institutional support that is requisite to a successful collaboration 125 and, therefore, did not work out. Child advocacy, to which we next turned, was also an area in which the first author had no prior experience. However, the lawyering skills and values that had been critical to other forms of litigation and that would have been brought to collaboration in domestic violence work are equally appropriate to advocating for children. A year's preparation time was adequate for an experienced lawyer and teacher to develop the competence to teach and supervise in this area.

Another consideration in choosing a partner for a law school-based collaboration is how it will work for the students. In teaching in our Civil Practice Clinic - a general litigation and legal services model clinic - the first author had seen, time and again, that students asked whether the tasks that they were called on to undertake were really tasks done by lawyers, or "merely" social work. 126 Too often, law students saw their relationship to social work students as hierarchical, with the law students on top. We were concerned that if we partnered only with social work students and supervisors, too much time and energy would be spent on simply addressing that issue, to the detriment of many others, and might create resentment that would actually hamper the students' learning to collaborate across disciplines. Moreover, that hierarchical attitude could get in the way of seeing their clients, and their clients' families, as equals - something that is critical to being open to accepting them as they are, and providing the holistic service that is at the heart of effective lawyering. The solution that we reached was to build a collaboration including medical professionals as well as social workers from the start. We believed that medical students would not "take

124 While the first author was in practice, almost all of his practice - employment discrimination law - was not an area that he had studied in law school. Indeed, in the firm in which he had practiced for many years, all of the practice group chairs spent most of their time working in subspecialty areas that they had not studied in law school either. For example, although the real estate group dealt with the law of property, its most challenging and important work was in designing and negotiating financial arrangements among participants to a transaction. That is in large measure due to the fact that the law, and thus the practice of law, evolves over time, and lawyers must evolve with it if they are to serve their clients effectively.

125 See infra Part III.C (discussing institutional and administrative challenges to collaboration).

126 See Jane Aiken and Stephen Wizner, Law as Social Work, 11 WASH. U. J.L. EO POL'Y 63, 63 (2003) (arguing that the lawyer's defensive response to the idea that the work they do is "social work" is troublesome). 
orders" from law students, and that law students would not attempt to "assign" things to the medical students. Rather, they would start out seeing each other as equals, and proceed from that point to learn how to collaborate.

In practice, it has become clear that some of these initial concerns were overblown. While there have been occasions on which law students have attempted to pass off certain tasks on the social work students, or complained of having to do what they deemed to be social work, for the most part that has not happened. When it has, the social work students, sometimes after requesting support from supervisors, have had little problem in engaging the errant law student in dialogue about the need to collaborate as equals. Perhaps this is because of the social work supervisors we have had, perhaps because of the students we have had. And perhaps it is because we, as supervisors, understand and work hard to make visible to clinic students that the demands of the cases and the clients' needs so clearly implicate the knowledge and skills of social workers. Also, the law students, who are quickly drawn to the needs of their clients, and develop a commitment to help them - something they learn both explicitly and implicitly in law school - recognize that without partnering with social workers, they simply cannot achieve the same results for those clients.

By now there have been so many cases in which the law students realize that without the medical students or social work students they would have been at a loss to address the real needs of their clients, we seldom are faced with a law student who thinks that the social work or medical student is merely an "add on" to the "legal team."

\section{Collaborators Who Are Complementary}

When we first sought to create a collaboration across disciplines, we were aware that an attempt at such a clinical relationship at Penn Law fifteen years earlier had not worked out. The relationship had been abandoned, in large measure because there was no agreed-upon model for integrating the social work students in to the law school clinical course, nor as to the role of the social work supervisor. Because the initial plan had been to partner with a good friend who was a member of the faculty of University's Medical School and ran a clinic for battered women, which gave her the opportunity to collaborate with lawyers, mental health professionals, social workers and law enforcement personnel, we expected that many of these concerns would not affect our relationship; she already had a framework from which we could start building a collaborative relationship. Unfortunately, when that didn't work out, a new concern emerged. Without knowing anyone in a position to be a partner in such an endeavor well enough to have confidence that the investment would pay off, moving forward became a challenge. The potential colleague from the Medical School fortunately recommended and introduced us to a colleague with whom she had worked for many years, the director of the child abuse program of Children's Hospital of Philadelphia (CHOP). As director, she collaborates with lawyers and social workers on a daily basis. Similarly, in seeking out a social work supervisor, recommendations sought from several individuals in the child welfare community finally led to collaboration with a person who had extensive experience in child welfare work and in crossdisciplinary collaboration. The collaboration ultimately has been successful because, from the beginning, everyone was ready to collaborate.

Collaboration requires the ability to work closely, trust one another, acknowledge that one's partners have essential assets to bring to the work, be open to learning from one another, be open to ceding control to one's partners, and perhaps most importantly, listening. Moreover, in an interdisciplinary collaboration, each partner, at least at the start, does not have sufficient knowledge of the other's discipline to know in a specific case whether the knowledge and judgment brought to the problem by that partner is appropriate. Thus, it is imperative that the partners to an interdisciplinary collaboration are compatible professionally 
and personally, flexible, and firmly committed to investing the time and patience necessary to make the collaboration work.

\section{B. Respecting Partners and their Respective Professions}

Even when a collaborative arrangement has been successfully negotiated, there exists the potential for serious problems between professionals used to working within discrete and separate professional frameworks. This results at least partially because, in addition to the particular subject matter expertise a professional holds with respect to her practice, she holds also an obligation to uphold principles of responsible practice within her profession. Because each profession's obligations differ, and at times may even conflict, partnerships between professionals from different disciplines can be challenging.

For the legal professional, the Model Rules of Professional Conduct proscribe certain lawyer-non-lawyer professional partnerships that may hinder the attorney's capacity for independent and reasoned judgment. 127 While this rule is designed primarily to prevent fee-splitting arrangements with non-lawyers for the provision of legal services, it exists also in part to ensure that the lawyer exercises independent judgment in rendering legal services. ${ }^{128}$ The rule does not prohibit collaboration, but does demand a particular level of care when working collaboratively with non-lawyers. Therefore, a lawyer who chooses to collaborate with a non-lawyer to provide better service to her clients must ensure that she makes decisions independently. ${ }^{129}$ She must also ensure that she upholds other professional responsibilities to her clients, including the duty of confidentiality. 130 Ordinarily, when the lawyer conducts her work in consultation with non-lawyer assistants, those assistants are bound by the same professional obligations of the lawyer. ${ }^{131}$ In the context of collaboration, however, where professionals are most effective by approaching a problem on equal footing, questions unavoidably arise as to whether the collaborating professionals ought to be bound by these rules, particularly when they conflict with the obligations inherent to their own profession. ${ }^{132}$ We do not submit that there are easy or comprehensive solutions to these problems. They will inevitably exist, just as questions regarding potentially inappropriate professional conduct exist for any lawyer in practice with other lawyers. A common conundrum is one in which our client, especially one old enough to form and defend an opinion about what she wants to do, 133 is faced

127 MODEL RULES OF PROF'L CONDUCT R. 5.4(b) (2006) ("A lawyer shall not form a partnership with a nonlawyer if any of the activities of the partnership consist of the practice of law."); see also, generally, WILLIAM WESLEY PATTON, LEGAL ETHICS IN CHILD CUSTODY AND DEPENDENCY PROCEEDINGS: A GUIDE FOR JUDGES AND LAWYERS 7, 27, 69 (Cambridge Press: NY 2006) (acknowledging the particular difficulties that ethics rules create for lawyers in these proceedings).

128 MODEL RULES OF PROF'L CONDUCT R. $5.4 \mathrm{cmt}$. (2006) (noting the dual aims of this rule).

129 See MODEL RULES OF PROF'L CONDUCT R. 2.1 (2006).

130 MODEL RULES OF PROF'L CONDUCT R 1.6 (2006) (defining the scope of the duty of confidentiality).

131 MODEL RULES OF PROF'L CONDUCT R. 5.3 (2006) (imputing the obligations of the lawyer on nonlawyer assistants).
132 In the context of child welfare work, this challenging question arises particularly with respect to the tension between a lawyer's obligation of confidentiality and the existence of mandated reporter laws obliging both social workers and physicians to report suspected abuse or neglect. While the lawyer can only break confidentiality to disclose such information under very narrow circumstances, permitted only when there is "reasonably certain death or substantial bodily harm," the standard applicable to mandated reporters requires disclosure at a much lower threshold. Very real questions arise as to which standard a physician or social worker in a child welfare-related collaboration ought to follow.

133 The provisions of Rule 1.14 (Client With Diminished Capacity) of the ABA Model Rules of Professional Responsibility and the Pennsylvania Rules of Professional Responsibility simply do not provide much help in deciding where on the slippery slope of "diminished capacity" one's actual client falls, and thus whether it is appropriate to seek the appointment of a guardian ad litem. See MODEL RULES OF PROF'L CONDUCT R. 1.14 (b). 
with a situation in which other adults think that her best interests are served by a solution different from the one she prefers. We choose to deal with these problems by acknowledging that they will arise, making students aware of the professional responsibilities attributable to their respective professions, ${ }^{134}$ and then investing the time, analytical effort and trust necessary in order to handle together any potential conflicts that arise. One constant component of this approach is to stress, and re-stress, the importance of the counseling function. While the role of counselor is common to each of the three disciplines, ${ }^{135}$ we have found that social work students are much better prepared as professionals to counsel their clients than are law students or medical students. We believe that our approach has worked because it is predicated upon each participant's deep understanding of and respect for the indispensable professionals with whom they collaborate.

\section{Overcoming Institutional and Administrative Challenges}

Universities are usually composed of a number of "colleges," or "schools," each with its own faculty, its own schedule, and, worse yet, its own budget. Moreover, different schools may be located at distant locations on campus, on separate campuses, or even in different parts of the city. Thus, creating an academic offering that will include faculty and students from more than one school can be a challenge. The initial proposed collaboration to provide advocacy and counseling for victims of domestic abuse failed even though both of the proposed collaborators are at the same university, and all of the schools involved are within walking distance of each other on the same campus. The failure occurred largely because certain individuals whose administrative approval and support were required failed to consider how the vastly different schedules of medical, law, and social work students might be harmonized, what sort of academic requirements and credit would be appropriate for the medical students, and how to give the medical school faculty member "credit" for the teaching and supervision that she would be doing. This last item involves the trade-off of required teaching time and money, because if she was to be given credit for participation in this interdisciplinary course, additional details had to be settled. For example, we had to consider how much a collaborator should be compensated. After all, she would be co-teaching, not handling the workload alone. Additionally, we had to think about how to compare teaching in this course with other, more traditional teaching done by other medical faculty. Finally, we had to consider whether anyone, and if so who, would teach the courses that she had previously taught and where the money would come from to compensate that person.

These are all real problems, and in many traditional academic institutions, formidable ones. We spent a long time planning our current collaboration, and have been fortunate. The dean of our School of Social Policy and Practice has been very supportive, actually raising the money from a donor to pay for our social work supervisor. The pediatrician with whom we co-teach is on the faculty of two institutions, and was willing, and proved able, to negotiate that this work would be part of her teaching responsibility on the one that is not our medical school. She has also included her residents and fellows in the course as part of their

134 Law students, for example, are required to read the Model Rules of Professional Conduct concurrent with their enrollment in the seminar; additionally, seminar time is devoted to discussing mandated reporter statutes that bind social work and medical professionals. While we have done no studies, it has always seemed to the faculty that discussion of these issues - how to represent a pre-teen or teen aged client whose articulated goals seem adverse to their best interests and well being - usually occupy more time than virtually any other issue.
135 See MODEL RULES OF PROF'L CONDUCT R. 2.1 (stating the lawyer's counseling obligation); National Association of Social Workers Code of Ethics R. 1.07(h) (noting confidentiality in the counseling role of social workers); American Medical Association Code of Medical Ethics, Opinion E-10.01 (including among the "Fundamental Elements of the Patient-Physician Relationship" the right of patients to seek information and advice from their physician). 
educational experience. To facilitate this collaboration, we agreed to have the majority of the classes at CHOP. This year, the Director of Training for the Pediatric Psychiatry Fellowship recognized the training value of participation, and agreed to have her fellows participate as well. And, finally, the Law School and the School of Social Policy and Practice, with our urging, agreed to provide academic and field-work credit for the social work students in the course. It was not easy; it took time, planning and negotiation. But in the end it worked. The fact that there are other interdisciplinary clinics throughout the country attests to the fact that it can be done. And who better to do the planning, negotiation and advocacy necessary to persuade others to support this collaboration, than lawyers?

\section{CONCLUSION - WORKING TOWARDS CHANGE}

One thing that is becoming clearer to me as I progress in this clinic is the need for the law to be as "available" as possible in terms of being accessible to all of the people that it affects. In law school, students gain a skewed perspective of the legal process, as appellate cases with complex procedural machinations, and high financial stakes are the order of the day. The life of a litigation associate in a major law firm can inculcate similar values and perspectives, as it may be difficult for that young attorney to put a "face" to their client or to truly understand the practical ramifications of their case to any degree beyond the financial bottom line. This clinic has illustrated for me a theoretical notion that I had only acknowledged [sic] in passing - that most of the law in this country is practiced on an individual level - and the lives of those people are directly affected by the legal process. ${ }^{136}$

If the model we propose here is accepted, it demands that legal educators and administrators also accept a diversion from traditional approaches of educating lawyers. But, "[c]hange is the process by which the future invades our lives, and [change] is important ... not merely from the grand perspectives of history, but also from the vantage point of the living, breathing individuals who experience it."137 The effective lawyer must constantly adjust her approach to suit the needs of her client in a dynamically changing legal environment in which new legal issues consistently arise. Crucial to successful modification is educating lawyers who understand, embrace, and most importantly can adapt to the change. Interdisciplinary endeavors are an increasingly important mechanism by which different groups can together absorb and address the changes that affect a population they are both working to serve. We posit here that an intense interdisciplinary experience - which promotes and expects students to perform high-quality professional work, and to do so in a collaborative model otherwise unknown in law school; motivates powerful emotional attachments to that work; and sometimes results in successes for a population that has the capacity to demand more than a student knows she can give - generates long-term critical professional learning and fosters an ability for collaboration. The process tends towards better outcomes for clients and collaborators alike because we understand, by engaging our clients habitually and by incorporating the wisdom of the living breathing individuals with whom we collaborate, how we can change together to create more just and favorable results.

136 Clinic Law Student (2003) (journal entry, on file with

137 ALVIN TOFFLER, FUTURE SHOCK 1 (1970). author). 


\section{APPENDIX}

\section{THE FAMILY OF BABY “M”}

Baby M., a 2 1/2 yr old child, had been reported to the county child protective services agency, known as The Department of Human Services (DHS) as having an elevated blood lead level. The family would neither speak with the investigator from the Department of Human Services (DHS), nor permit him in the home, so DHS filed a Petition in Court seeking an order to compel mother's cooperation. Our Clinic (CLINIC) was appointed to represent the child. Mother failed to appear at the first hearing, and had not responded to her court appointed lawyers letter. The Court continued the case for a week. By the time the case was back in court, DHS had been to the house, determined that mother \& child had moved next door with Maternal Grandmother (MGMa), and visited there.

Mother and child appeared at court for the continued hearing, accompanied by the MGMa, and counsel for Mother. We observed, and were concerned about, MGMa's verbal interactions with the child, always critical ("You are a bad girl.") and threatening ("If you don't come here right away, I'm going to hit you."), etc. Mother did not intervene; however, Mother and child seemed connected to each other. In court we learned that mother had recently had another child ("INFANT"), and also has a 15 yr. old son ("TEEN") who lives with them, and goes to school. However, neither of them was the subject of the Dependency Petition.

Because MGMas house also had old and peeling paint - probably lead based - DHS removed M. and placed her with her paternal grandparents (PGp), who live a few blocks from mother. DHS reported that the PGp agreed that Mom could visit whenever she wished. Mother agreed to cooperate, and signed a Release permitting us to obtain the child's blood lead level reports. We made arrangements to make a home visit. Mother also agreed to accept Services for Children in Their Own Home (SCOH), and other services from DHS. We offered, and the court approved, having the child, M, seen, evaluated, and followed at Children's Hospital of Philadelphia (CHOP).

During the telephone call to make arrangements for the home visit, when our student asked Mother a question, she handed the phone to her mother (MGMa), who then took over the conversation. At that point she said that they would not have the child go to CHOP because there was nothing wrong with her, and they were not going to let strangers experiment with her.

The home visit was done by our $3 \mathrm{~d}$ yr. law student, and our 4th year medical student. The medical student is also a former Peace Corps worker in West Africa. When they returned, they reported that MGMa's house was filthy, and overrun by roaches. Mother and MGMa. were dressed in dirty unkempt attire, MGMa in a night gown. The home had a space heater in the middle of the living room. The roach problem was the worst that either student had ever seen, with roaches in, on, and coming out of every piece of furniture, drawer and closet. Also, much of the furniture, including the child's bed, was broken. Trash was piled and strewn everywhere.

DHS took the position that the Baby M. could not return home until the house was exterminated for roaches, cleaned, and the lead paint problem was abated. Mother's lawyer complained that that would take weeks to accomplish. Mother's lawyer also said that there was serious hostility between Mother and MGMa on the one hand, and the paternal grandparents, the former alleging that the Father suffered from AIDS. By the time the home visit took place, Mother's lawyer had arranged to get them paint to paint over the lead paint, and that had, pretty much, been done. 
We then arranged to have mother and all 3 children accepted immediately at Peoples' Emergency Center (a highly regarded, full service residential center for homeless mothers with children) to live there, temporarily, pending the extermination of the house. Mother's lawyer said that she would recommend that; however, mother refused.

PGp were both retired. Their home was clean, well organized, filled with family photographs, and adequate in every way. They were careful and attentive to M.; however, there was not evidence of much hugging and other forms of emotional nurturing. Baby M. expressed the desire to be with her mother, saying that she would clean Maternal Grandmother's house so that she could return home. Also, although the PGp confirmed that Mother, who does not work, was welcome to visit any time, they said that she came only once a week.

Our investigation also included interviewing Father. Based upon the conversations with father and PGp, our students concluded that it was highly likely that Father does suffer from AIDS, and that it is a sufficiently advanced state to suggest that he was HIV infected when M. was conceived. Consequently, we requested, through Mother's lawyer, that $\mathrm{M}$. be tested. We were told that she had been, at birth, and was negative. We asked for a release for the child's medical records, and were told they would be provided. When we finally got the records, there was no indication of HIV testing. Mother continued to insist that it had been done, and refused to agree to have current testing for $\mathrm{M}$.

At the follow-up hearing three (3) months later, while we were still trying to find money to pay for an exterminator, and about to ask the Court to order Mother to have baby M. tested for HIV, Mother's lawyer argued that the child was not neglected, her best interests were not being served because it was more harmful to her to remain in the home of her PGp, than it would be to have her living in the MGMa's home with her mother and siblings, and that Mother's constitutional and statutory rights to parent her children as she sees fit is being violated.

Mother contends that because M. is neither abused nor neglected she must be returned immediately.

(What recommendations would you make to the court; and why?)

\section{THE LAW}

The Pennsylvania. Juvenile Act, 42 Pa. C.S.A. $§ 6301$, et seq., ${ }^{138}$ and the Pennsylvania Child Protective Services Act, $23 \mathrm{~Pa}$. C.S.A $\S 6301$, et seq., ${ }^{139}$ generally govern proceedings to protect children who have been abused 140 or neglected, ${ }^{141}$ or are otherwise found to be dependent, 142 i.e., without proper parental care, or supervision, including school attendance as required by law. ${ }^{143}$

The burden of proof in a dependency case is on the party seeking to have the child adjudicated dependent and/or removed from the home, to prove dependency by "clear and convincing evidence." 144 Once a court has adjudicated a child dependent, that child is subject to supervision by the court which may be in the home, or after commitment to the custody of the Child Protective Services Agency (CPSA) and removal

138 Pennsylvania Juvenile Act, 42 Pa. C.S.A. $\$ 6302-6365$, et seq. (2007)

139 Pennsylvania Child Protective Services Law, 23 Pa. C.S.A. $\$ 6302-6385$ (2006)

14023 Pa. C.S.A. $\$ 6302(a)$
14142 Pa. C.S.A. $\$ 6302$

142 Id.

143 Id.

14442 Pa. C.S.A. \$6341(c) 
from the home, in an appropriate out of home placement. Before a court can order a child to be removed from her/his home, the CPSA is required to make reasonable efforts to avoid such removal, and once the child is removed, the CPSA must make reasonable efforts to return the child to her/his parent. ${ }^{145}$

In any proceeding which could result in the removal of a child from its home, temporarily or permanently, the court must appoint a guardian for the child in the litigation (Guardian ad litem [GAL]), and the guardian must be a lawyer. The guardian must pursue the "best interests of the child."146

If a child is adjudicated dependent, and committed to the CPSA, the CPSA is responsible for providing for all of the child's needs, to assure its safety, health and well being, ${ }^{147}$ and for making reasonable efforts to re-unify the child with the parents. ${ }^{148}$ Implicit in the CPSA's responsibility for the protection of children is its responsibility to provide reasonable assistance to parents in recognizing and remedying conditions harmful to their children and in fulfilling their parental duties more adequately. 149

Once a child has been adjudicated dependent the court must review the case not less than once every six months, 150 and include in its order (a) whether the child remains dependent, (b) whether the child is safe and her/his needs are being met - whether in the home, or in a placement - (c) whether it is contrary to the child's health, safety and well being to remain where she/he is - at home or in placement - and (d) whether the CPSA has made reasonable efforts to prevent placement, or if the child is in an out-of-home placement to re-unify the child with the parents. 151

\section{Social Work Considerations}

As described in the preamble to the Code of Ethics of the National Association of Social Workers, the mission of the social work profession is rooted in a set of core values. These core values, embraced by social workers throughout the profession's history, are the foundation of social work's unique purpose and perspective:

- service

- social justice

- dignity and worth of the person

- importance of human relationships

- integrity

- competence

While looking at the facts laid out in the case, we must make sure we look at this family through the lens of these core values, and ask ourselves these questions (and more!)

1.Is the child safe? Are her needs being met?

2.Do we have any responsibility to the other children in the home?

3. What direct supports can we help mother with in improving her home so she can improve her living conditions?

14542 Pa. C.S.A. $\$ 6351$

14642 Pa. C.S.A. $\$ 6311(a)$

14723 Pa. C.S.A. $\$ 6373(a)(7)$

14823 Pa. C.S.A. $\$ 6373(a)(5)$
14923 Pa. C.S.A. $\$ 6374(b)$

15042 Pa. C.S.A. $\$ 6351($ e)

15142 Pa. C.S.A. $\$ 6351$ 
4.How can we encourage the mother/daughter relationship while apart from each other?

5. What is the quality of the interaction between mother and child(ren) and how can this be improved? What in these facts suggests this is an area that needs support?

6.How can we assist the family in overcoming their concerns about our involvement and "strangers experimenting" with their daughter?

7.How do we honor the "dignity and worth" of our client and her family when they are so hostile to our concerns about their situation?

\section{Thoughts to consider:}

If a child is safe, than how do we justify separating her from her mother - how much could our own values about 'what a home should look like' be affecting our judgment?

If the child is HIV positive, how does this affect our reaction to mother, father, and the child, and how does it affect our position and work with this family?

Poverty is an overarching issue here - what can we as social workers do in direct support around this issue for this family as well as on the macro/societal level for all families in similar situations.

\section{Physician \& Patient}

You are the physician for "M", a 2 yr old child, who you see for the first time in your clinic. You notice that M has not had routine care and order lab work, including a lead level, which is missing from her record. You discover that the lead level is high. On your exam, you also notice that $\mathrm{M}$ is small for her age and that she does not talk much. When you question the mother, you find out that they are living in a home without running water. You report M's lead status and living conditions to DHS. Your colleagues at Penn Law are appointed as child advocates for $\mathrm{M}$ and her siblings. They contact you for additional information, including her medical records, and you ask them to keep you aware of developments that may affect the children's health. During this conversation, you learn that DHS investigated your report and discovered 2 additional children in the home, a 4 month old baby "J" and a 15 year old boy "R" and opened a case on them as well. DHS filed a dependency petition. The child advocate also tells you about their first home visit.

At this visit mother indicated that the baby was sick "a lot" and that the 15 year old (who was not at home but unaccounted for) had not attended school in about a year because he's a "dummy" and she "could not make him go". She also said she used crack cocaine "once in a while" to help her "get her mind off her problems". She suspected her 15 year old was using, and perhaps dealing, drugs as well. M was observed to be very hyper and to have no comprehensible speech. Her clothes appeared too small and very dirty.

The home was observed to have some peeling paint (believed to be lead based on M.'s lead levels) and a few exposed wires in the ceiling. The home had a space heater in the middle of the living room because the heat had been shut off for non-payment. There was water but not hot water. The roach problem was excessive. Also, much of the furniture, including M's bed which she shared with Mother, was broken. Baby J. slept in a bassinet and the R. on the couch. Stuff was piled and strewn everywhere. Mother seemed very depressed with little affect and when asked, admitted she had depression but was not being treated. She feels overwhelmed by her responsibilities. None of the children's fathers are involved and Mother alleges that M's father "had AIDS." 
You agree to care for all three children, and are asked to testify about their health at the first hearing, where you hear the Judge defer adjudication and order DHS to "help" the family or he will place all three children at the next hearing. You want to assist in any way that you can.

\section{Medical Considerations}

- Lead levels are generally checked in children routinely at between 9-12 months and sometimes again at 2 years. Screening is necessary because lead toxicity can have significant adverse effects on the development of the brain and nervous system in children. Beyond these initial screenings, children are typically assessed for risk of lead exposure throughout early childhood.

$>12 \%$ of $1-2$ y.o. children have an elevated lead level. Higher risk populations include those:

- In which there is inadequate data on the rate of increased blood lead levels

- Residing in the $>27 \%$ of housing built in USA prior to 1950 that contain lead

- By two years of age,

- a child should know several words

- The child also should be able to combine these in 2-4 word sentences.

- A listener should be able to understand $50 \%$ of what a child is saying

- Father with suspected HIV/AIDS and a 4 month old who is sick a lot and a mother who is doing crack cocaine

- If father has AIDS, there would potentially be transmission to mother

- There is potential for perinatal (in utero) transmission of HIV to fetus, which could affect M or J

- The situation raises obvious concerns for J \& M to get tested for HIV - treatment for very young infants can be quite effective.

- Another consideration is whether mom breastfeeds J

- Crack cocaine could be ingested by J in breast milk

- J at 4 months of age is unable to make the first line antibody defense to infection (IgA). The infant's immature immune system isn't ready to produce this until 6 months of age. A breastfeeding infant can usually get IgA from a portion of the mother's breast milk. Formula does not contain IgA. If J is not breastfed, and is exposed to infection, J may be more susceptible.

- Beyond the sanitation concerns, cockroaches are highly allergenic. We don't have evidence of allergenic/asthmatic reactions of the older children or mother but it may be something to follow. This would not be expected to account for J's being sick because the immature immune system also does not mount a huge response to allergens.

- Cataracts in children can be congenital (present at birth) or acquired (develop later). Acquired cataracts may be related to an underlying disease. While the definitive treatment for cataracts is removal, when underlying disease is present the cataracts may reoccur after surgery. A medical evaluation to look for underlying disease would be prudent. 


\section{Using the problem of "THE FAMILY OF 'BABY M" as a teaching exercise}

This case has twice been used as the basis for an exercise to demonstrate the value of multi-disciplinary collaborations, each time with an audience primarily of lawyers. We divided the audience in to three groups: lawyers, social workers, and doctors. All three get the introductory case description. Each group then also gets the additional information that is discipline-specific - "The Law" for the lawyers; "Social Work Considerations" for the social workers, and "Physician \& Patient" and "Medical Considerations" for the doctors. The three groups then go off and discuss the situation by themselves, returning after about 15 minutes to share their advocacy proposals with the others.

Each time that the exercise was done, all three groups decided, independently, that the goal should be that the child would be returned to her mother; however after that, they were on very different pages. Each time, the lawyers group focused on the conflict between the child's interests and the mother's, and identified the things that the mother should be required to do to get her baby back. The medical folks had everyone in the family undergoing some test, assessment or treatment, but made no suggestion about anything having to do with interpersonal communications or relationships. The social workers advocated counseling, and talking together to discuss where to go and what everyone needed to do, individually and together, to enable the family to live together. They also recommended that resources be made available to address the roach situation, and to assist Mother to do what she needed to do while obtaining counseling, as well as an assessment for depression. The group as a whole then discussed the ideal "package" of responses using some from each group to demonstrate that the collaboration can, but the individual disciplines acting alone cannot, provide what the child and family needed to go forward constructively. 